\title{
Performance investigation of a solar-assisted direct contact membrane distillation system
}

\author{
Young-Deuk Kim ${ }^{\text {a,* }}$, Kyaw Thu ${ }^{\text {a }}$, Noreddine Ghaffour ${ }^{\text {a }}$, Kim Choon Ng a,b \\ ${ }^{a}$ Water Desalination and Reuse Center, 4700 King Abdullah University of Science and Technology, \\ Thuwal 23955-6900, Saudi Arabia. \\ ${ }^{\mathrm{b}}$ Department of Mechanical Engineering, National University of Singapore, 10 Kent Ridge Crescent, \\ Singapore 117576, Singapore \\ * Corresponding author.
}

Tel.: +966 2808 4970. E-mail address: youngdeuk.kim@kaust.edu.sa (Y.-D. Kim).

\begin{abstract}
This paper presents a solar-assisted direct contact membrane distillation (DCMD) system with novel energy recovery concepts for a continuous 24-hour-a-day operation. A temperature modulating scheme is introduced to the solar-thermal system that supplies feed seawater to the DCMD modules. This scheme attenuates extreme temperature fluctuations of the feed water by storing the collected energy during solarpeak hours and reutilizing it throughout the day. Thus, the energy savings is realized yet the feed seawater temperature is maintained within the preferred range. Additionally, the system employs heat recovery from the permeate and brine streams to the feed seawater. The simulations for such a system with a shelland-tube type DCMD modules are carried out to examine the spatial property variations and the sensitivity of system performance (i.e., transmembrane pressure, permeate flux and performance ratio) to the operating conditions (inlet temperature and flow rate) and the fiber dimensions (fiber length and packing density). It is found that there are trade-off between mean permeate flux and performance ratio with respect to permeate inlet temperature and flow rate and between total distillate production and performance ratio with respect to packing density. For the solar-assisted DCMD system having evacuated-tube collectors of $3360 \mathrm{~m}^{2}$ with $160 \mathrm{~m}^{3}$ seawater storage tanks and 50 DCMD modules, the annual solar fraction and collector efficiency are found to be $77 \%$ and $53 \%$, respectively whilst the overall permeate production capacity is $31 \mathrm{~m}^{3} /$ day. The overall specific thermal energy consumption of DCMD system with heat recovery is found to be $436 \mathrm{kWh} / \mathrm{m}^{3}$ and it is about $43 \%$ lower as compared to the system without heat recovery. It is observed that the specific thermal energy consumption decreases significantly by $55 \%$ with increased collector area from $1983 \mathrm{~m}^{2}$ to $3360 \mathrm{~m}^{2}$ whereas the specific electrical energy consumption increases slightly by $16 \%$.
\end{abstract}

Keywords: Hollow fiber direct contact membrane distillation (DCMD); Solar-assisted desalination; Heat recovery (HR); Temperature modulating (TM); Modeling

\section{Introduction}


Membrane distillation (MD) is a thermal separation process that involves transport of only water vapor or other volatile molecules through a microporous hydrophobic membrane and operates on the principle of vapor-liquid equilibrium as a basis for molecular separation. The driving force of the process is the vapor partial pressure difference created by temperature gradient imposed between the liquid-vapor interfaces. MD has potential applications in many areas of scientific and industrial interest, yielding highly purified permeate and separating contaminants from liquid solutions [1].

The MD has a number of potential advantages over conventional desalination processes such as multi-stage flash (MSF), reverse osmosis (RO) and multi-effect distillation (MED). The key advantages of MD are; (i) lower operating temperature and hydrostatic pressure, (ii) nearly $100 \%$ (theoretical and practical) rejection of non-volatile solute, (iii) lower vapor space resulting in low mass transfer resistance between the liquid and condensate phases, (iv) low sensitivity to salt concentration and (v) performance not limited by high osmotic pressure or concentration polarization [1-5]. In particular, the potential of MD process for desalination is a remarkably high water vapor flux up to $80 \mathrm{~kg} / \mathrm{m}^{2} \mathrm{~h}$ with a direct contact membrane distillation (DCMD) in the laboratory-scale experiments [6,7], as compared to typical RO fluxes in the range of $25-50 \mathrm{~kg} / \mathrm{m}^{2} \mathrm{~h}$ [8]. Nevertheless, pretreatment devices, hybrid strategies, process design and new membrane manufacturing technologies for MD processes are needed for long-term and efficient operations. Since MD process is a non-isothermal, furthermore, MD modules must be designed to ensure good flow conditions in terms of flow regime, configuration and uniformity, high packing density and low pressure drop as well as good thermal stability and heat recovery [2]. In particular, the hollow fiber membrane module has the highest packing density of all module configurations, while it has a higher pressure drop, due mainly to a high ratio of fiber length to diameter [4]. Nevertheless, much studies have been devoted to hollow fiber membranes due to their high mass transfer rate, resulting from the high surface density area $[1,2,4,6,9,10]$. Another important factor of the hollow fiber module is the deficiency in fluid flow through the effective mass transfer area due to the flow maldistribution, which is caused by the polydispersity of fiber diameter at the tube side and the non-uniformity of fiber packing at the shell side [9]. It has been shown that the randomness of fiber packing in shell side can result in a permeate flux reduction up to $58 \%$ corresponding to a packing density of $40 \%$ as compared to the module of uniform packing $[9,10]$. For MD module with non-isothermal characteristics, therefore, systematic modeling on spatial variations and dependence of the heat and mass transfers on the membrane module configurations, membrane dimensions and operating conditions are important for predicting the process performance and designing the system optimally, but it is rarely studied or even ignored [2].

Phase-change desalination processes require significant quantities of energy to achieve separation. The MD is one of the phase-change desalination processes, but it can be more economic and potential process for seawater desalination especially when equipped with low-grade waste heat or alternative energy sources such as wind, solar and geothermal energies. Among renewable energy sources, solar energy can be harvested with a solar collector for preheating seawater and producing the thermal energy required to drive the phase-change process. Recently, MD process for desalination gained much interest due to these attractive features, especially when coupled with solar energy or utilizing low-grade heat source [4,11-17]. In an attempt to be environmentally friendly and yet minimize the energy input to the 
desalination process, a solar-assisted hollow fiber DCMD desalination system with novel energy recovery scheme is proposed. A temperature modulating scheme is implemented in the solar-thermal system to supply consistent heat source for the DCMD modules that employs the heat recovery from permeate and brine streams to the feed seawater. Solar-thermal system coupled with temperature modulating scheme enables to store the energy recovered from the brine and permeate streams during solar-peak hours. Thus, the operating hours at which the supply hot seawater maintains the desired temperature has been prolonged since the system stores and reuses the energy during the operation throughout the day.

The objectives of this paper are to design a solar-assisted DCMD desalination system with the heat recovery (HR) and temperature modulating (TM) schemes, and to develop a rigorous mathematical model for the prediction of system performance with respect to both transmembrane flux and thermal efficiency. The proposed system comprises of evacuated-tube collectors, hot seawater storage tanks, brine and permeate storage tanks, auxiliary heater and cooler (pre-set to supply hot seawater and cold permeate at a DCMD module), plate heat exchangers for heat recovery and shell-and-tube type hollow fiber DCMD modules. The simulations of DCMD module are first carried out to investigate the spatial property variations and the sensitivity of the process performance to the operating conditions including the temperature and flow rate of both feed and permeate sides and the fiber dimensions such as fiber length and packing density. The long-term performances of solar-assisted DCMD system based on the baseline membrane configuration are then examined with respect to collector area and storage tank volume using the ASHRAE standard flow rate. The system performance is reported in terms of the annual solar fraction and collector efficiency, as well as the transmembrane flux (or overall permeate production rate) and performance ratio.

\section{Theoretical background}

\subsection{Theoretical minimum energy for desalination}

All desalination systems require substantial energy input to split the dissolved salts from the sea or brackish water. However, in terms of thermodynamics, there exists the minimum energy requirement or simply the thermodynamic limit regardless of the system used, to perform desalting. Several approaches evaluating the theoretical minimum energy for desalination have been well established [18,19]. Among these approaches, the differential work, $d W$, needed for obtaining a differential amount of fresh water, $d V$, can be expressed by Eq. (1a), and then the total work per volume of freshwater produced $\left(V_{1}-V_{2}\right), W$, is given by Eq. (1b), denoting the initial volume of the salt solution as $V_{1}$ and the final volume as $V_{2}$.

$d W=\pi_{\mathrm{os}} d V$

$W=\frac{1}{V_{1}-V_{2}} \int_{V_{1}}^{V_{2}} \pi_{\mathrm{os}} d V$

where the osmotic pressure $\pi_{\mathrm{os}}$ can be calculated with the following formula:

$\pi_{\mathrm{os}}=i \phi c R T$

where $i$ is the number of ions produced during dissociation of solute, which is also called the dissociation factor or the van't Hoff factor, and $\phi$ is the osmotic coefficient. 
For any water recovery, the minimum work is related to the theoretical work for zero recovery, $W_{0}$, and the minimum work for desalination can be expressed in terms of the water recovery, $r$, noting that $r=\left(V_{1}-V_{2}\right) / V_{1}$, as follows [19]:

$W=\frac{W_{0}}{r} \ln \frac{1}{1-r}$

Stoughton and Lietzke [18] showed that the theoretical minimum energies for zero recovery are 0.77 , 0.82 and $0.87 \mathrm{kWh} / \mathrm{m}^{3}$ for seawater with salt concentration of $3.45 \mathrm{wt} \%$ and temperatures of $50^{\circ} \mathrm{C}, 75^{\circ} \mathrm{C}$ and $100^{\circ} \mathrm{C}$, respectively. The theoretical minimum work for desalting seawater as a function of water recovery for seawater temperatures of $25^{\circ} \mathrm{C}$ and $80^{\circ} \mathrm{C}$ is presented in Fig. 1. The salinity of feed seawater is set to be $4.5 \mathrm{wt} \%$ because the salinities of the Red Sea and the Persian Gulf are about 4.0-4.5 wt\%. It is shown that the theoretical minimum energy increases dramatically at high water recoveries. The theoretical minimum work for zero recovery is 0.93 and $1.07 \mathrm{kWh} / \mathrm{m}^{3}$ at $25^{\circ} \mathrm{C}$ and $80^{\circ} \mathrm{C}$, respectively, and its value required to desalt seawater ranges from about $1-3 \mathrm{kWh} / \mathrm{m}^{3}$ over the range of practical recoveries.

Recent developments in RO technology have led to significant savings in both capital and operating costs for seawater desalination. For seawater RO system, the specific energy usage is typically about 2-6 $\mathrm{kWh} / \mathrm{m}^{3}$ with energy recovery devices at the conditions of $3.2-3.5 \mathrm{wt} \% \mathrm{NaCl}$ solution, $55 \mathrm{bar}, 25^{\circ} \mathrm{C}$ and 10-30\% recovery [20]. For brackish water RO, energy usage is comparatively lower, about 0.5-2 $\mathrm{kWh} / \mathrm{m}^{3}$, because the energy required for desalination is proportional to the feed water salinity [21]. As stated before, however, if the MD system having a relatively high mass flux is coupled with low-grade waste heat or alternative energy sources such as solar and geothermal energies, its specific energy consumption required for desalting seawater can be significantly decreased and competed with RO.

\subsection{System description}

A schematic diagram of the solar-assisted DCMD desalination system is shown in Fig. 2. The system comprises the solar-thermal system with TM unit, the HR unit and the shell-and-tube type DCMD modules.

The solar-thermal system has two circuits i.e., the primary solar circuit for the collection of solar energy and the secondary circuit that supplies the hot seawater to the DCMD modules through the four seawater storage tanks and the TM unit which adjusts hot seawater supply to the DCMD modules during the mid-day hours when the seawater temperature in the storage tank- 4 is higher than the desired feed temperature, resulting in energy savings for use in the late-afternoon and night-time hours. During the mid-day hours, that is, the seawater from storage tank-4 is mixed with the makeup seawater to attain the desired temperature by controlling valve operation (CV1, CV2 and CV3), as shown in Table 1. More details on the flow rate control scheme are introduced in Section 2.6. These two circuits are thermally communicated via a plate heat exchanger. The four storage tanks are constructed in a top-to-bottom arrangement to achieve thermal stratification yet fulfill thermal demand of the load in terms of hot seawater supply. Whenever the storage tank-4 temperature falls below the desired feed temperature, the maximum possible portions of the energy demand is supplemented by keeping the discharge mass flow rate equals to the desired feed flow rate and the rest of the energy demand is supplied by the auxiliary. 
The makeup seawater through the HR unit (HX2, HX3 and HX4) that recovers heat from the brine and permeate is supplied to the mixing junction as soon as hot seawater from the storage tank-4 is withdrawn for the load requirement. This arrangement assures that the storage tank is always fully filled. The seawater drawn from storage tank-1 is mixed at the mixing junction with makeup seawater, and then a mixture flows into heat exchanger (HX1). The return hot seawater is sent back to the tanks dynamically based on the temperature, i.e., it is supplied to the tank with temperature closest to but less than the return hot seawater. This filling scheme ensures the storage tank-4 temperature to be the highest. The operation of the primary pump is controlled based on the collector outlet temperature and the inlet temperature of the plate heat exchanger in secondary circuit. As shown in Table 1, it is activated whenever the temperature of the former is higher than that of the latter or for heating up the heat transfer fluid (Syltherm 800, silicone-based fluid, Dow Corning Co.) with a deactivation of secondary pump after sunrise. The silicone-based fluid is used due to its low fouling potential $\left(1.5 \times 10^{-5} \mathrm{~m}^{2 \circ} \mathrm{C} / \mathrm{W}\right)$, low freeze point $\left(-40^{\circ} \mathrm{C}\right)$, high-temperature stability $\left(400^{\circ} \mathrm{C}\right)$, long life $(10$ years or more), no corrosivity, low odor and low acute oral toxicity.

The baseline configurations for solar-assisted DCMD system are; (i) the local solar insolation and ambient temperature inputs (Jeddah, Saudi Arabia), (ii) a flow rate of heat transfer fluid (HTF) through the headers of collector based on ASHRAE standards, (iii) a pre-set hot seawater and cold permeate demands and (iv) the dynamic augmentation of seawater temperature by auxiliary when the supply temperature from solar tank drops below the set point.

The mathematical models for the analysis of solar-assisted DCMD desalination system include the hollow fiber DCMD, the meteorological data, the evacuated-tube collector, the seawater, brine and permeate storage tanks and the plate heat exchanger. For the development of the models, it is assumed that the system has well-insulated pipes with no leaks and its configuration and control are close to the ones considered in the development of the model.

\subsection{Hollow fiber DCMD}

A schematic representation of the DCMD module is illustrated in Fig. 3(a). The hollow fiber DCMD module consists of an array of porous hydrophobic membranes, assembled together in a shell-and-tube module. The heat and mass transfer across the membrane is typically obtained by countercurrent flowing the hot feed through the tube side and the cold permeate through the shell side of the module, as shown in Fig. 3(b).

\subsubsection{Transmembrane flux}

DCMD involves mass transfer of water vapor through a microporous membrane, coupled with heat transfer across the membrane and through the boundary layers adjacent to the membrane surfaces, as shown in Fig. 3(b). The heat transfer process includes the heat transferred through the boundaries of the feed side $\left(Q_{\mathrm{f}}\right)$ and the permeate side $\left(Q_{\mathrm{p}}\right)$, and across the membrane $\left(Q_{\mathrm{m}}\right)$.

The convection heat transfer through the feed boundary layer can be given as: 
$Q_{\mathrm{f}}=h_{\mathrm{f}} A_{\mathrm{f}} \alpha\left(T_{\mathrm{f}}-T_{\mathrm{f}, \mathrm{m}}\right)$

where $A_{\mathrm{f}}=1$ and $\alpha=\pi N_{\mathrm{f}} d_{\mathrm{i}} \cdot T_{\mathrm{f}}$ and $T_{\mathrm{f}, \mathrm{m}}$ are the bulk feed and membrane/feed interface temperatures, respectively. The heat transfer coefficient $h_{\mathrm{f}}$ for the laminar and transitional flows, especially at higher mass flow rate and lower packing density conditions, in the tube side is estimated by [22,23]:

$$
\begin{aligned}
& N u_{\mathrm{f}}=\frac{h_{\mathrm{f}} d_{\mathrm{i}}}{k_{\mathrm{f}}}=4.36+\frac{0.036 \operatorname{RePr} d_{\mathrm{i}} L_{\mathrm{f}}}{1+0.0011\left(\operatorname{RePr} d_{\mathrm{i}} L_{\mathrm{f}}\right)^{0.8}}, R e<2100 \\
& N u_{\mathrm{f}}=\frac{h_{\mathrm{f}} d_{\mathrm{i}}}{k_{\mathrm{f}}}=0.116\left(\operatorname{Re}^{2 / 3}-125\right) \operatorname{Pr}^{1 / 3}\left[1+\left(d_{\mathrm{i}} / L_{\mathrm{f}}\right)^{2 / 3}\right], R e>2100
\end{aligned}
$$

where $k_{\mathrm{f}}$ is the thermal conductivity of the bulk feed.

The convection heat transfer through the permeate boundary layer can be calculated using

$$
Q_{\mathrm{p}}=h_{\mathrm{p}} A_{\mathrm{p}} \alpha\left(T_{\mathrm{p}, \mathrm{m}}-T_{\mathrm{p}}\right)
$$

where $A_{\mathrm{p}}=d_{\mathrm{o}} / d_{\mathrm{i}} . T_{\mathrm{p}}$ and $T_{\mathrm{p}, \mathrm{m}}$ are the temperatures of the bulk permeate and at the permeate side of the membrane, respectively. For the permeate circulating in the shell side of the module, both parallel and cross flow may occur simultaneously. The heat transfer coefficient $h_{\mathrm{p}}$ at the shell side is evaluated by Groehn's correlation [24]:

$$
N u_{\mathrm{p}}=\frac{h_{\mathrm{p}} d_{\mathrm{h}}}{k_{\mathrm{p}}}=0.206(\operatorname{Re} \cos \alpha)^{0.63} \operatorname{Pr}^{0.36}
$$

where $k_{\mathrm{p}}$ is the thermal conductivity of the bulk permeate and $\alpha$ is the yaw angle, which varies between $0^{\circ}$ for pure cross flow and $90^{\circ}$ for pure parallel flow. The characteristic dimension of heat transfer at the shell side refers to the hydraulic diameter of shell $d_{\mathrm{h}}, d_{\mathrm{h}}=d_{\mathrm{o}}(1-\phi) / \phi$, which is a function of the packing density of the module $\phi, \phi=N_{\mathrm{f}}\left(d_{\mathrm{o}} / d_{\mathrm{s}}\right)^{2}$ [25].

The heat transfer through the membrane can be described by two mechanisms: latent heat of vaporization and sensible heat conduction. The convection heat transfer through the membrane pores is assumed to be negligible since the heat transfer by convection accounts for only $0.6 \%$ of the total heat transferred across the membrane and at most $6 \%$ of the total heat lost by dissipation in the membrane [26]. Therefore, the heat transfer across the membrane can be written as:

$Q_{\mathrm{m}}=A_{\mathrm{m}} \alpha\left[J \Delta H\left(T_{\mathrm{m}}\right)+\frac{k_{\mathrm{m}}}{\delta_{\mathrm{m}}}\left(T_{\mathrm{f}, \mathrm{m}}-T_{\mathrm{p}, \mathrm{m}}\right)\right]$

with $A_{\mathrm{m}}=d_{\mathrm{lm}} / d_{\mathrm{i}}, d_{\mathrm{lm}}=\left(d_{\mathrm{o}}-d_{\mathrm{i}}\right) / \ln \left(d_{\mathrm{o}} / d_{\mathrm{i}}\right)$ and $k_{\mathrm{m}}=\varepsilon k_{\mathrm{v}}+(1-\varepsilon) k_{\mathrm{s}}$, where $k_{\mathrm{v}}$ and $k_{\mathrm{s}}$ refer to the thermal conductivities for solid (polymer) and gases in the pores (air and water vapor), respectively. Here, $k_{\mathrm{s}}$ is generally one order of magnitude greater than $k_{\mathrm{v}}$ [27]. $\Delta H$ is the enthalpy of evaporation at the mean temperature across the membrane $T_{\mathrm{m}}, T_{\mathrm{m}}=\left(T_{\mathrm{f}, \mathrm{m}}+T_{\mathrm{p}, \mathrm{m}}\right) / 2$.

At steady state, the overall heat transfer through the membrane is given by $Q_{\mathrm{f}}=Q_{\mathrm{p}}=Q_{\mathrm{m}}$

The mass transport is described by assuming a linear relationship between the mass flux $(J)$ and the 
vapor pressure difference through the membrane distillation coefficient $(C)$. The transmembrane mass flux $J$ in DCMD can be written as follows:

$J=C\left(P_{\mathrm{f}, \mathrm{m}}-P_{\mathrm{p}, \mathrm{m}}\right)$

where $P_{\mathrm{f}, \mathrm{m}}$ and $P_{\mathrm{p}, \mathrm{m}}$ are the water vapor pressures at the liquid/vapor interface on the feed and the permeate sides of the membrane, respectively. Due to the presence of dissolved species with molar concentration $x_{\mathrm{f}}$ at the feed side, the reduction in the vapor pressure can be described according to Raoult's law

$P_{\mathrm{f}, \mathrm{m}}=\left(1-x_{\mathrm{f}, \mathrm{s}}\right) P_{\mathrm{w}, \mathrm{m}}$

where $P_{\mathrm{w}, \mathrm{m}}$ is the water vapor pressure (in Pa) with no dissolved species in the water and estimated using the Antoine equation [28]

$\log _{10}\left(133.3 P_{\mathrm{w}, \mathrm{m}}\right)=8.07131-\frac{1730.63}{T+233.426}$

where $T$ is the temperature in ${ }^{\circ} \mathrm{C}$.

In this study, the polyvinylidene fluoride (PVDF) membrane produced by phase separation (i.e., phase inversion) process is used, which typically has a broad pore size distribution around the mean. As shown in Table 2, the nominal pore diameter of the membrane is $0.2 \mu \mathrm{m}$, but the largest pores are slightly greater than $1 \mu \mathrm{m}$ [29], and thus it is proved that a lot of pores are much larger than the mean free path of water vapor molecules $\left(0.11 \mu \mathrm{m}\right.$ at $\left.60^{\circ} \mathrm{C}\right)$ [30]. In this case, the Poiseuille flow mechanism should be considered in describing the mass transfer of membrane. Therefore, a Knudsen diffusion-Molecular diffusion-Poiseuille flow transition model for a membrane with a larger pore size is applied for describing the vapor flux of pure water across the membrane, as illustrated in Fig. 4. The membrane distillation coefficient can be expressed as follows [15,29-32]:

$C=\left(R_{\mathrm{K}}+R_{\mathrm{M}}\right)^{-1}+R_{\mathrm{P}}^{-1}$

where $R_{\mathrm{K}}^{-1}=C_{\mathrm{K}}\left(M_{\mathrm{w}} / R T_{\mathrm{m}}\right)^{0.5}$ with $C_{\mathrm{K}}=r_{\mathrm{m}} \varepsilon / \tau \delta_{\mathrm{m}}, \quad R_{\mathrm{M}}^{-1}=C_{\mathrm{M}}\left(D M_{\mathrm{w}} / P_{\mathrm{aM}} R T_{\mathrm{m}}\right)$ with $C_{\mathrm{M}}=\varepsilon / \tau \delta_{\mathrm{m}}$ and $R_{\mathrm{P}}^{-1}=C_{\mathrm{P}}\left(M_{\mathrm{w}} P_{\mathrm{m}} / \mu R T_{\mathrm{m}}\right)$ with $C_{\mathrm{P}}=r_{\mathrm{m}}^{2} \varepsilon / \tau \delta_{\mathrm{m}}$, respectively. The values of $C_{\mathrm{K}}, C_{\mathrm{M}}$ and $C_{\mathrm{P}}$ are given in Table 2 [29]. $P_{\mathrm{am}}$ is the log-mean air pressure at both sides of the membrane. $P_{\mathrm{m}}$ is the mean water vapor pressure inside the membrane, $P_{\mathrm{m}}=\left(P_{\mathrm{f}, \mathrm{m}}+P_{\mathrm{p}, \mathrm{m}}\right) / 2$. The binary diffusion coefficient $D$ is estimated by Fuller-Shettler-Giddings (FSG) empirical equation [33], which can be simplified to the form given in $D=1.19 \times 10^{-4}\left(T_{\mathrm{m}}^{1.75} / P_{\mathrm{m}}\right)$.

\subsubsection{Transport models of feed and permeate sides}

To describe the hollow fiber module transport behavior, a mathematical model is formulated by writing mass, momentum and energy balances. The transport equation is derived for the retentate as well as for the permeate side of the module as the flux depends on feed and permeate side conditions [32]. The transport equation is derived based on the following assumptions: (i) steady incompressible flow under constant operating conditions, (ii) unidirectional lubrication flow of Newtonian fluid for feed in the tube, 
(iii) negligible axial diffusion compared to convection, (iv) the fibers distributed uniformly on the shell side, (v) negligible heat generation due to viscous dissipation and (vi) negligible heat loss to the ambient environment.

The mass, momentum and energy balances for the feed side in the tube on simplification yield the following equations in terms of velocity, composition, pressure and temperature.

$\frac{1}{X_{\mathrm{f}}} \frac{d v_{\mathrm{f}}}{d z}-\frac{v_{\mathrm{f}}}{X_{\mathrm{f}}^{2}}\left(\frac{M_{\mathrm{s}}}{\rho_{\mathrm{s}}}-\frac{M_{\mathrm{w}}}{\rho_{\mathrm{w}}}\right) \frac{d x_{\mathrm{f}}}{d z}=-\frac{4 J d_{\mathrm{o}}}{M_{\mathrm{f}} d_{\mathrm{i}}^{2}}$

$\frac{x_{\mathrm{f}}}{X_{\mathrm{f}}} \frac{d v_{\mathrm{f}}}{d z}+\frac{v_{\mathrm{f}} M_{\mathrm{w}}}{\rho_{\mathrm{w}} X_{\mathrm{f}}^{2}} \frac{d x_{\mathrm{f}}}{d z}=0$

$\frac{d P_{\mathrm{f}}}{d z}=-\frac{32 \mu_{\mathrm{f}} v_{\mathrm{f}}}{d_{\mathrm{i}}^{2}}$

$\frac{d \rho_{\mathrm{f}} v_{\mathrm{f}} c_{\mathrm{p}, \mathrm{f}} T_{\mathrm{f}}}{d z}=-\frac{4 Q_{\mathrm{f}}}{N_{\mathrm{f}} \pi d_{\mathrm{i}}^{2}}$

The velocity, composition, pressure and temperature for the feed side are subject to the boundary conditions:

$v_{\mathrm{f}}(0)=v_{\mathrm{f}, \mathrm{in}}, \quad x_{\mathrm{f}}(0)=x_{\mathrm{f}, \mathrm{in}}, \quad P_{\mathrm{f}}\left(L_{\mathrm{f}}\right)=P_{0}, \quad T_{\mathrm{f}}(0)=T_{\mathrm{f}, \mathrm{in}}$

where $P_{0}$ is the ambient atmospheric pressure at both outlets of the fluids.

In the permeate side, the mass, momentum and energy balances provide coupled differential equations in terms of velocity, pressure and temperature.

$\frac{d \nu_{\mathrm{p}}}{d z}=-\frac{4 N_{\mathrm{f}} J d_{\mathrm{o}} X_{\mathrm{p}}}{M_{\mathrm{p}}\left(d_{\mathrm{s}}^{2}-N_{\mathrm{f}} d_{\mathrm{o}}^{2}\right)}$

$\frac{d P_{\mathrm{p}}}{d z}=\frac{32 \mu_{\mathrm{p}} v_{\mathrm{p}}}{d_{\mathrm{h}}^{2}}$

$\frac{d \rho_{\mathrm{p}} v_{\mathrm{p}} c_{\mathrm{p}, \mathrm{p}} T_{\mathrm{p}}}{d z}=-\frac{4 Q_{\mathrm{p}}}{\pi\left(d_{\mathrm{s}}^{2}-N_{\mathrm{f}} d_{\mathrm{o}}^{2}\right)}$

where the composition term is neglected due to the theoretical $100 \%$ rejection of non-volatile solute in the DCMD process. The detailed derivations of the model equations are explained in [32].

The differential equations for velocity, pressure and temperature of the permeate side are subject to the boundary conditions:

$v_{\mathrm{p}}\left(L_{\mathrm{f}}\right)=v_{\mathrm{p}, \text { in }}, P_{\mathrm{p}}(0)=P_{0}, T_{\mathrm{p}}\left(L_{\mathrm{f}}\right)=T_{\mathrm{p}, \text { in }}$

In order to evaluate the performance of a DCMD module with non-isothermal characteristics, the mean permeate flux $\left(J_{\mathrm{M}}\right)$ and the performance ratio $(P R)$ are expressed as

$$
\begin{aligned}
& J_{\mathrm{M}}=\frac{1}{L_{\mathrm{f}}} \int_{0}^{L_{\mathrm{f}}} J(z) d z \\
& P R=\frac{1}{L_{\mathrm{f}}} \int_{0}^{L_{\mathrm{f}}} \eta(z) d z
\end{aligned}
$$

where $J(\mathrm{z})$ is the local permeate flux as expressed in Eq. (10). $\eta(\mathrm{z})$ is the local performance ratio, defined as the ratio of the vaporization heat associated with the transmembrane flux to the heat transferred across 
the membrane, and given by

$$
\eta(z)=\frac{J(z) \Delta H\left(T_{\mathrm{m}}\right)}{J(z) \Delta H\left(T_{\mathrm{m}}\right)+\left(k_{\mathrm{m}} / \delta_{\mathrm{m}}\right)\left[T_{\mathrm{f}, \mathrm{m}}(z)-T_{\mathrm{p}, \mathrm{m}}(z)\right]}
$$

Since the prolongation of the fiber length or the increase of packing density will increase the membrane area, the total distillate production (TPD) of a DCMD module based on the fiber outer diameter [32,34] is evaluated in Section 3.1.4 and defined as

$T P D=J_{\mathrm{M}} N_{\mathrm{f}} \pi d_{\mathrm{o}} L_{\mathrm{f}}$

\subsubsection{Solution procedure}

Thermophysical properties of water and seawater are obtained from [35]. The set of coupled ordinary differential equations (ODEs) for tube side feed flow, i.e., Eqs. (14)-(17), and for shell side permeate flow, i.e., Eqs. (19)-(21), are discretized with the finite volume method and solved in conjunction with the boundary conditions, i.e., Eqs. (18) and (22), and the characterization of the membrane, i.e., Eqs. (4), (6), (8) and (9) for heat transfer and Eqs. (10)-(13) for mass transfer.

In order to solve the system of ODEs with splitting boundary values, Broyden's method [36], which is a quasi-Newtonian method for numerical solution of nonlinear equations, has been employed. It is noted that the unknown feed side pressure $P_{\mathrm{f}}(0)$ and permeate side temperature $T_{\mathrm{p}}(0)$ and velocity $v_{\mathrm{p}}(0)$ at $z=0$ are supposed, transforming the boundary value problem to an initial value problem. The vapor flux and the corresponding velocity, concentration, temperature and pressure distributions for each control volume are computed iteratively using the method of successive substitution until the relative difference between two consecutive iterations is less than $10^{-10}$. Then, the solution is marched forward until $z=L_{\mathrm{f}}$, and then the guessed values of $P_{\mathrm{f}}(0), T_{\mathrm{p}}(0)$ and $v_{\mathrm{p}}(0)$ are updated. This procedure is repeated until the boundary conditions in Eqs. (18) and (22) are met within an absolute error of $10^{-6}$. A uniform partition of the physical domain is used with a step size of $4 \times 10^{-3} \mathrm{~m}$. The obtained solution is confirmed to be independent of finer discretization. The characteristics and baseline operating conditions of the hollow fiber membrane module used are reported in Table 2 [29,32].

\subsection{Solar radiation and ambient temperature}

For the local solar insolation input, the monthly average hourly global radiation incident upon a tilted surface is estimated with several existing empirical theories, based on the monthly average daily global radiation $\left(\mathrm{MJ} / \mathrm{m}^{2} /\right.$ day) with the 22-year average data of the NASA SSE model [37]. Here, the global radiation consists of beam and diffuse components.

Based on the monthly average daily global radiation on a horizontal surface, the monthly average daily diffuse radiation is first calculated by means of a monthly average diffuse fraction correlation, as a function of monthly average clearness index and sunset (or sunrise) hour angle [38]. The monthly average hourly diffuse and global radiations are then obtained from the monthly average daily diffuse and global radiations on a horizontal surface by using the ratio of hourly global to daily global radiation which is a function of the day length and the hour in question [38,39]. Finally, the monthly average hourly global 
irradiation on a tilted surface is estimated using Hay-Davies-Klucher-Reindl (HDKR) anisotropic diffuse radiation model that considers the circumsolar diffuse and horizon brightening components on a tilted surface [40-43], and given by

$$
I_{\mathrm{d}, \mathrm{T}}=I_{\mathrm{d}}\left\{\left(1-A_{\mathrm{i}}\right)\left(\frac{1+\cos \beta}{2}\right)\left[1+f \sin ^{3}\left(\frac{\beta}{2}\right)\right]+A_{\mathrm{i}} R_{\mathrm{b}}\right\}
$$

where $A_{\mathrm{i}}\left(=I_{\mathrm{b}} / I_{\mathrm{o}}\right)$ is an anisotropic index as a function of the transmittance of the atmosphere for beam radiation and $f=\left(I_{\mathrm{b}} / I_{\mathrm{h}}\right)^{1 / 2}$.

Then, the global radiation on the tilted surface is calculated as:

$$
I_{\mathrm{T}}=\left(I_{\mathrm{b}}+I_{\mathrm{d}} A_{\mathrm{i}}\right) R_{\mathrm{b}}+I_{\mathrm{d}}\left(1-A_{\mathrm{i}}\right)\left(\frac{1+\cos \beta}{2}\right)\left[1+f \sin ^{3}\left(\frac{\beta}{2}\right)\right]+I_{\mathrm{h}} \rho_{\mathrm{g}}\left(\frac{1-\cos \beta}{2}\right)
$$

where the geometric factor $R_{\mathrm{b}}\left(=\cos \theta / \cos \theta_{\mathrm{z}}\right)$ is the ratio of beam radiation on the tilted surface to that on a horizontal surface at any time.

The detailed procedure for estimating solar radiation incident upon a tilted surface is discussed in [44]. The monthly average hourly ambient temperature is based on the measured data [45]. For the simulation, the monthly average hourly meteorological data like beam and diffuse irradiances and ambient temperatures are derived into polynomial and rational equations, respectively, which are expressed as a function of local time as follows:

$$
G_{\mathrm{bord}}=\sum_{k=0}^{L} a_{k} t^{k}, T_{\mathrm{a}}=\sum_{k=0}^{M} a_{k} t^{k} /\left(\sum_{k=0}^{N-1} b_{k} t^{k}+t^{N}\right)
$$

with $L=6$ and $M=N=3$. The coefficients ( $a$ and $b$ ) included in Eq. (29) are determined by using a conjugate gradient method (CGM) [46].

Fig. 5 shows the monthly average hourly ambient temperature and the global irradiance on the tilted surface obtained from the aforementioned solar radiation model. The maximum monthly average hourly ambient temperature and global irradiance are about $38^{\circ} \mathrm{C}$ in June and about $940 \mathrm{~W} / \mathrm{m}^{2}$ in April, respectively.

\subsection{Evacuated-tube collector (ETC)}

The instantaneous efficiency of evacuated-tube collector (ETC) is defined as the ratio between the useful energy delivered over aperture area and the total irradiance of the collector aperture as the following [47]:

$$
\eta_{\mathrm{c}}=\frac{q_{\mathrm{u}}}{A_{\mathrm{a}} G_{\mathrm{T}}}=\frac{\dot{m}_{\mathrm{c}} c_{\mathrm{p}, \mathrm{c}}\left(T_{\mathrm{c}, \mathrm{o}}-T_{\mathrm{c}, \mathrm{i}}\right)}{N_{\mathrm{c}} A_{\mathrm{a}} G_{\mathrm{T}}}
$$

The instantaneous collector efficiency at any incidence angle, which takes into account the incident angle modifiers, $K_{\theta \mathrm{b}}(\theta)$ and $K_{\theta \mathrm{d}}$, for beam and diffuser irradiances, can be calculated as:

$$
\eta_{\mathrm{c}}(\theta)=\eta_{0} K_{\theta \mathrm{b}}(\theta)+\eta_{0} K_{\theta \mathrm{d}}-c_{1} \frac{T_{\mathrm{m}}-T_{\mathrm{a}}}{G_{\mathrm{T}}}-c_{2} G_{\mathrm{T}}\left(\frac{T_{\mathrm{m}}-T_{\mathrm{a}}}{G_{\mathrm{T}}}\right)^{2}
$$


with $T_{\mathrm{m}}=\left(T_{\mathrm{c}, \mathrm{i}}+T_{\mathrm{c}, \mathrm{o}}\right) / 2 . K_{\theta \mathrm{b}}(\theta)$ is obtained by the McIntire approximation [48] as a function of the transversal and longitudinal incidence angle of beam irradiance. $K_{\theta \mathrm{d}}$ is a constant correction factor for the diffuse irradiance. Here, the efficiency parameters, $\eta_{0}, c_{1}$ and $c_{2}$ provided by manufacturer, are obtained from the efficiency tests under specified ambient temperature and operating conditions according to the European standard [49].

By combining Eqs. (30) and (31), the outlet temperature of ETC can be calculated as:

$$
\frac{q_{\mathrm{u}}}{A_{\mathrm{a}}}=\eta_{0} K_{\theta \mathrm{b}}(\theta) G_{\mathrm{b}}+\eta_{0} K_{\theta \mathrm{d}} G_{\mathrm{d}}-c_{1}\left(T_{\mathrm{m}}-T_{\mathrm{a}}\right)-c_{2}\left(T_{\mathrm{m}}-T_{\mathrm{a}}\right)^{2}-c_{3} \frac{d T_{\mathrm{m}}}{d t}
$$

The pressure drop across the collector can be estimated from the following equation [50]:

$$
\Delta P_{\mathrm{SC}}=\left(9.171 V^{2}+7.077 V\right) / 1000,0 \leq V \leq 6.5
$$

\subsection{Seawater storage tank}

The seawater storage tank model is based on a finite volume method for the simulation of the storage tank performance, considering thermal stratification. The model divides it along the longitudinal axis into $N$ finite volumes, each one having uniform temperature, as shown in Fig. 2. The temperature distribution of the stratified thermal storage tank $i$ is obtained by an energy balance on control volume $j$, which considers the convective and diffusive fluxes and the heat losses to the ambient environment, as follows:

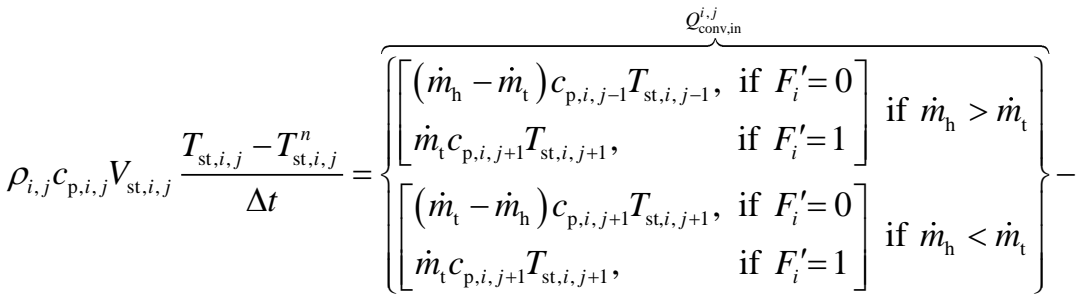

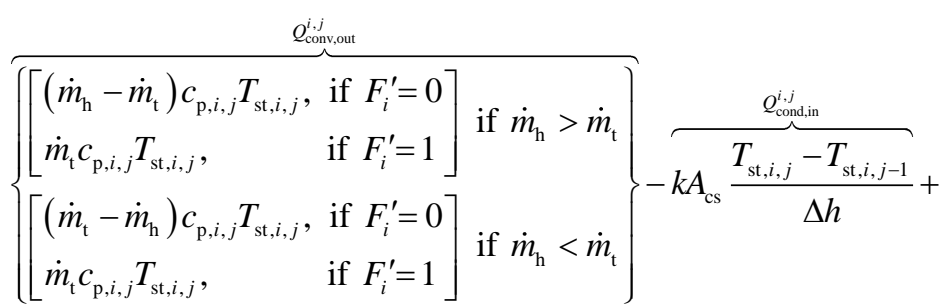

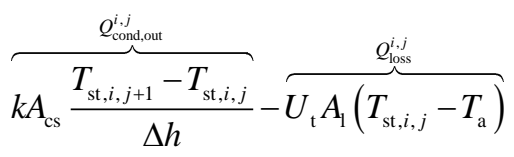

where $\Delta t$ is the time step, $\Delta h$ is the grid spacing, and $n$ denotes value at previous time step.

The energy balance equations for control volumes at the top $(j=1)$ and bottom $(j=N)$ of the storage tanks are expressed as, respectively: 


$$
\begin{aligned}
& \rho_{i, 1} c_{\mathrm{p}, i, 1} V_{\mathrm{st}, i, 1} \frac{T_{\mathrm{st}, i, 1}-T_{\mathrm{t}, i, 1}^{n}}{\Delta t}=\left\{\begin{array}{l}
\left\{\begin{array}{ll}
-\left(\dot{m}_{\mathrm{h}}-\dot{m}_{\mathrm{t}}\right) c_{\mathrm{p}, i, 1} T_{\mathrm{st}, i, 1}, & \text { if } F_{i}^{\prime}=0 \\
\dot{m}_{\mathrm{t}} c_{\mathrm{p}, i, 2} T_{\mathrm{st}, i, 2}, & \text { if } F_{i}^{\prime}=1
\end{array}\right] \text { if } \dot{m}_{\mathrm{h}}>\dot{m}_{\mathrm{t}} \\
{\left[\begin{array}{ll}
\left(\dot{m}_{\mathrm{t}}-\dot{m}_{\mathrm{h}}\right) c_{\mathrm{p}, i, 2} T_{\mathrm{st}, i, 2}, & \text { if } F_{i}^{\prime}=0 \\
\dot{m}_{\mathrm{t}} c_{\mathrm{p}, i, 2} T_{\mathrm{st}, i, 2}, & \text { if } F_{i}^{\prime}=1
\end{array}\right] \text { if } \dot{m}_{\mathrm{h}}<\dot{m}_{\mathrm{t}}}
\end{array}\right\}+\overbrace{F_{i} \dot{m}_{\mathrm{h}} c_{\mathrm{p}, \mathrm{h}} T_{\mathrm{h}, \mathrm{o}}}^{Q_{\mathrm{in}}^{i, 1}}+ \\
& Q_{\text {net }}^{i, 1}
\end{aligned}
$$

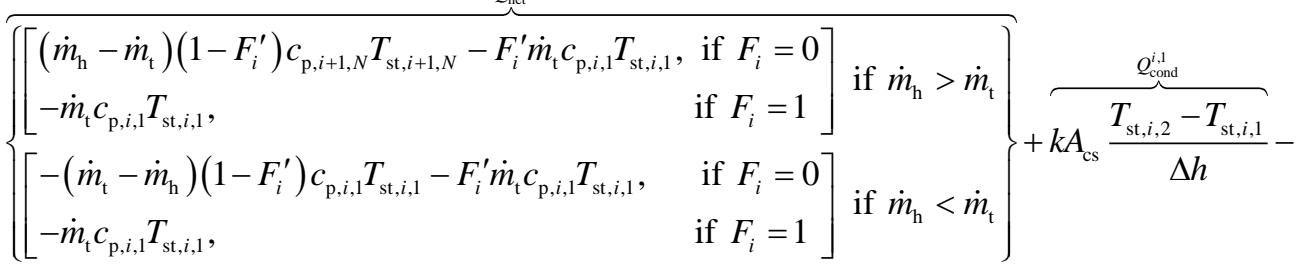

$$
\begin{aligned}
& \overbrace{U_{\mathrm{t}}\left(A_{\mathrm{cs}}+A_{1}\right)\left(T_{\mathrm{st}, i, 1}-T_{\mathrm{a}}\right)}^{Q_{\text {its }}^{\mathrm{i},}}
\end{aligned}
$$

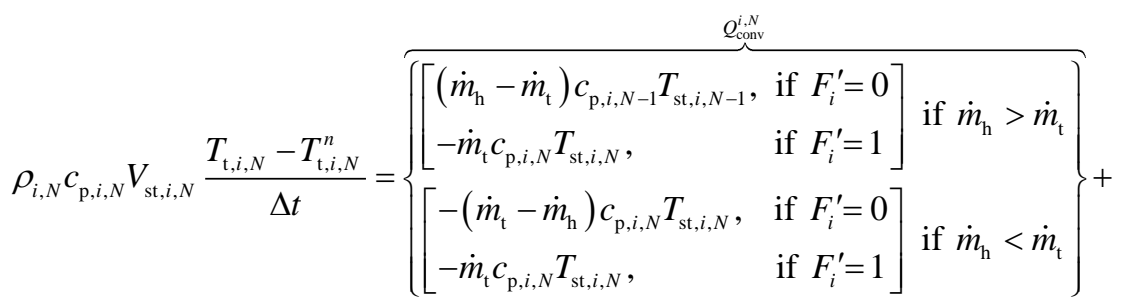

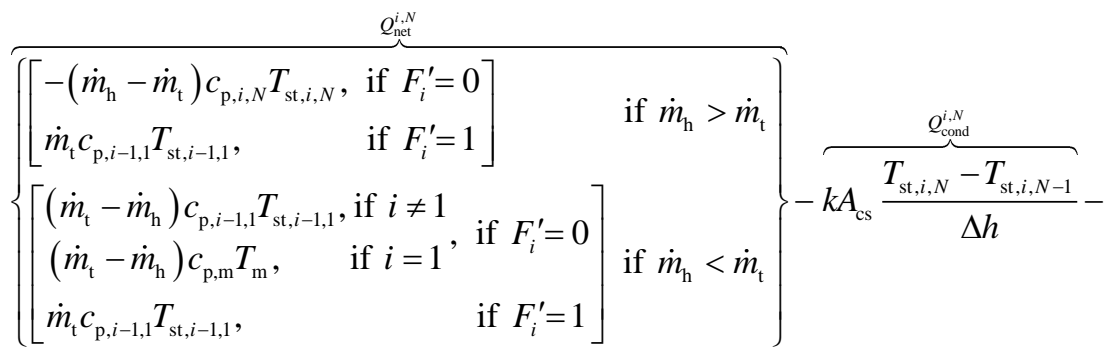

$$
\begin{aligned}
& \overbrace{U_{\mathrm{t}}\left(A_{\mathrm{cs}}+A_{1}\right)\left(T_{\mathrm{st}, i, N}-T_{\mathrm{a}}\right)}^{Q_{\mathrm{isss}}^{i, N}}
\end{aligned}
$$

The following control function $F_{i}$ defines which storage tank receives seawater from the plate heat exchanger.

$$
F_{i}= \begin{cases}1, & \text { if } T_{\mathrm{h}, \mathrm{o}}<T_{\mathrm{st}, i+1,1}, i=1 \\ 1, & \text { if } T_{\mathrm{st}, i, 1} \leq T_{\mathrm{h}, \mathrm{o}}<T_{\mathrm{st}, i+1,1}, i=2,3 \\ 1, & \text { if } T_{\mathrm{h}, \mathrm{o}} \geq T_{\mathrm{st}, i, 1}, i=4 \\ 0, & \text { otherwise }\end{cases}
$$

The net flow between storage tanks can be determined by the following function:

$$
F_{i}^{\prime}=\left\{\begin{array}{l}
0, \quad i=1 \\
\sum_{j=1}^{i-1} F_{j}, \quad i=2-4
\end{array}\right.
$$

It is noted that the desired feed temperature $\left(T_{\mathrm{f}, \mathrm{in}}\right)$ and flow rate $\left(\dot{m}_{\mathrm{f}}\right)$ are kept constant by adjusting the storage discharge flow rate $\left(\dot{m}_{\mathrm{t}}\right)$ from the storage tank-4 and makeup seawater flow rate $\left(\dot{m}_{\mathrm{m}}\right)$, even if the storage tank-4 temperature is higher than the desired feed temperature $\left(T_{\mathrm{st}, 4,1}>T_{\mathrm{f}, \mathrm{in}}\right)$. Storage 
discharge flow rate and makeup seawater flow rate are determined by considering mass and energy balance at the mixing junction as follows:

$$
\begin{aligned}
& \dot{m}_{\mathrm{t}}=\dot{m}_{\mathrm{f}} \frac{c_{\mathrm{p}, \mathrm{fm}}\left(T_{\mathrm{f}, \mathrm{in}}-T_{\mathrm{m}}\right)}{c_{\mathrm{p}, \mathrm{ff}}\left(T_{\mathrm{st}, 4,1}-T_{\mathrm{f}, \mathrm{in}}\right)+c_{\mathrm{p}, \mathrm{fm}}\left(T_{\mathrm{f}, \mathrm{in}}-T_{\mathrm{m}}\right)} \\
& \dot{m}_{\mathrm{m}}=\dot{m}_{\mathrm{f}} \frac{c_{\mathrm{p}, \mathrm{ff}}\left(T_{\mathrm{st}, 4,1}-T_{\mathrm{f}, \mathrm{in}}\right)}{c_{\mathrm{p}, \mathrm{ff}}\left(T_{\mathrm{st}, 4,1}-T_{\mathrm{f}, \mathrm{in}}\right)+c_{\mathrm{p}, \mathrm{fm}}\left(T_{\mathrm{f}, \mathrm{i}}-T_{\mathrm{m}}\right)}
\end{aligned}
$$

When $T_{\mathrm{st}, \mathrm{t}, 1}>T_{\mathrm{f}, \mathrm{in}}$, the energy demand met by the solar energy can be calculated as,

$$
q_{\mathrm{s}}=\dot{m}_{\mathrm{t}} c_{\mathrm{p}, \mathrm{m}}\left(T_{\mathrm{st}, 4,1}-T_{\mathrm{m}}\right)=\dot{m}_{\mathrm{f}} c_{\mathrm{p}, \mathrm{fm}}\left(T_{\mathrm{f}, \mathrm{in}}-T_{\mathrm{m}}\right)
$$

On the other hand, if the storage tank-4 temperature falls below the desired feed temperature $\left(T_{\mathrm{st}, 4,1} \leq T_{\mathrm{f}, \mathrm{in}}\right)$, the maximum possible portions of the energy requirement can be met by keeping the storage discharge flow rate equals to the desired feed flow rate $\left(\dot{m}_{\mathrm{t}}=\dot{m}_{\mathrm{f}}\right)$, and the rest of the energy requirement is fulfilled by the auxiliary. In such case, the energy demand met by the solar energy and the required auxiliary energy are determined as,

$$
\begin{aligned}
& q_{\mathrm{s}}=\dot{m}_{\mathrm{f}} c_{\mathrm{p}, \mathrm{tm}}\left(T_{\mathrm{st}, 4,1}-T_{\mathrm{m}}\right) \\
& q_{\mathrm{a}}=\dot{m}_{\mathrm{f}} c_{\mathrm{p}, \mathrm{ft}}\left(T_{\mathrm{f}, \mathrm{in}}-T_{\mathrm{st}, 4,1}\right)
\end{aligned}
$$

The mixture temperature of the seawater from the bottom of the storage tank-1 and the cold makeup seawater in the secondary solar circuit is calculated using the following equation.

$$
T_{\mathrm{h}, \mathrm{i}}=\frac{\left(\dot{m}_{\mathrm{h}}-\dot{m}_{\mathrm{t}}\right) c_{\mathrm{p}, 1, N} T_{\mathrm{st}, 1, N}+\dot{m}_{\mathrm{t}} c_{\mathrm{p}, \mathrm{m}} T_{\mathrm{m}}}{\left(\dot{m}_{\mathrm{h}}-\dot{m}_{\mathrm{t}}\right) c_{\mathrm{p}, 1, N}+\dot{m}_{\mathrm{t}} c_{\mathrm{p}, \mathrm{m}}}
$$

In order to evaluate the annual thermal performance of solar-assisted DCMD system, the annual collector efficiency and solar fraction is given as follows:

$$
\begin{aligned}
& S E=\frac{Q_{\mathrm{u}}}{Q_{\mathrm{r}}}=\frac{\sum_{1}^{365 \text { days }} \int_{0}^{t=24 \mathrm{hr}} q_{\mathrm{u}} d t}{N_{\mathrm{c}} A_{\mathrm{a}} \sum_{1}^{365 \text { days }} \int_{0}^{t=24 \mathrm{hr}} G_{\mathrm{T}} d t} \\
& S F=\frac{Q_{\mathrm{s}}}{Q_{\mathrm{s}}+Q_{\mathrm{a}}}=\frac{\sum_{1}^{365 \text { days }} \int_{0}^{t=24 \mathrm{hr}} q_{\mathrm{s}} d t}{\sum_{1}^{365 \text { days }} \int_{0}^{t=24 \mathrm{hr}} q_{\mathrm{s}} d t+\sum_{1}^{365 \text { days }} \int_{0}^{t=24 \mathrm{hr}} q_{\mathrm{a}} d t}
\end{aligned}
$$

\subsection{Brine and permeate storage tanks}

A similar energy balance for the brine and permeate storage tanks provides the following finite differential equation for the control volume $j$ of the brine and permeate storage tanks. 


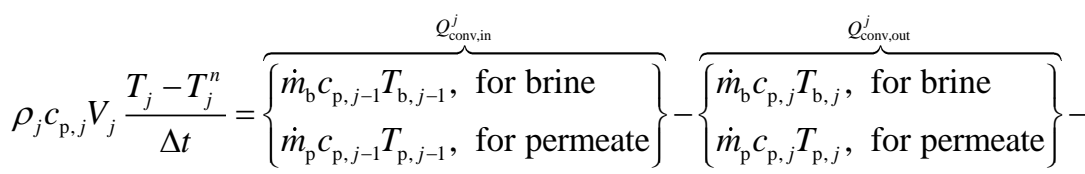

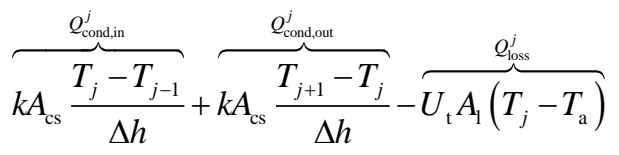

The finite differential equations for the control volumes at the top and bottom of the brine and storage tanks are expressed as, respectively:

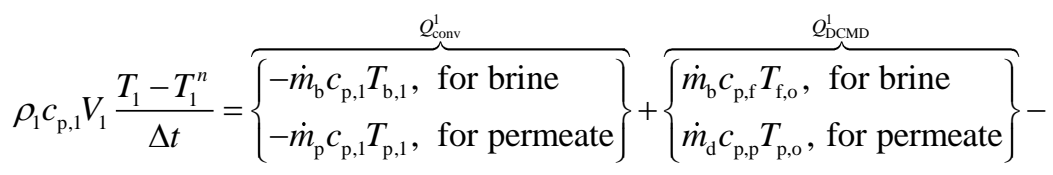

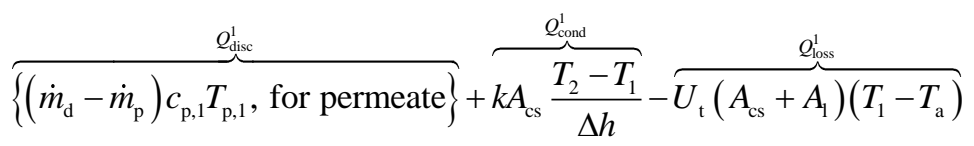

$\rho_{N} c_{\mathrm{p}, N} V_{N} \frac{T_{N}-T_{N}^{n}}{\Delta t}=\overbrace{\left\{\begin{array}{l}\dot{m}_{\mathrm{b}} c_{\mathrm{p}, N-1} T_{\mathrm{b}, N-1}, \text { for brine } \\ \dot{m}_{\mathrm{p}} c_{\mathrm{p}, N-1} T_{\mathrm{p}, N-1}, \text { for permeate }\end{array}\right\}}^{Q_{\text {conv }}^{N}} \overbrace{\left\{\begin{array}{l}\dot{m}_{\mathrm{b}} c_{\mathrm{p}, N} T_{\mathrm{b}, N}, \text { for brine } \\ \dot{m}_{\mathrm{p}} c_{\mathrm{p}, N} T_{\mathrm{p}, N}, \text { for permeate }\end{array}\right\}}^{Q_{\mathrm{N}}^{N}}-$

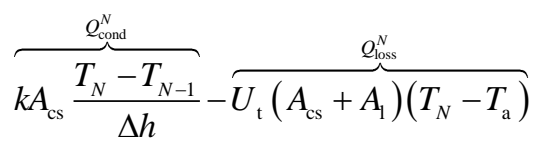

where the variables in the terms of heat accumulation, conduction and heat loss to the ambient environment are for the brine and permeate, respectively.

\subsection{Plate heat exchanger (PHE)}

With the inlet temperatures of the plate heat exchanger (PHE) in the solar-thermal system, Eqs. (32) and (44), and the brine- and permeate-heat-recovery heat exchangers, Eqs. (47)-(49), as represented in Fig. 2, the outlet temperatures are calculated by the effectiveness-number of transfer units (NTU) method. The effectiveness for the counter-flow PHEs with unmixed fluids is defined as a function of the heat capacity ratio, the number of transfer units and the flow arrangement [51],

$\varepsilon=\frac{\exp \left[\left(1-C^{*}\right) \mathrm{NTU}\right]-1}{\exp \left[\left(1-C^{*}\right) \mathrm{NTU}\right]-C^{*}}$

with $\mathrm{NTU}=U_{\mathrm{HX}} A_{\mathrm{HX}} / C_{\min }$ and $C^{*}=C_{\min } / C_{\max }$. The overall heat transfer coefficient across a plate can be calculated from the following equation:

$\frac{1}{U_{\mathrm{HX}}}=\frac{1}{h_{\mathrm{c}}}+\frac{1}{h_{\mathrm{h}}}+\frac{t}{k_{\mathrm{p}}}+R_{\mathrm{fc}}+R_{\mathrm{fh}}$

with $h_{i}=k_{i} / D_{\mathrm{e}}\left[C_{\mathrm{h}}\left(G_{\mathrm{ch}} D_{\mathrm{e}} / \mu\right)^{\mathrm{a}}\left(\mu c_{\mathrm{p}} / k_{i}\right)^{1 / 3}\right]$ for both cold $(i=\mathrm{c})$ and hot $(i=\mathrm{h})$ flows by neglecting viscosity correction factor [52], where $k_{i}$ refers to the thermal conductivity of the hot and cold fluids and the values of $C_{\mathrm{h}}$ and $a$ versus $R e$ for various chevron angles are given in [52]. $k_{\mathrm{p}}$ depicts the thermal 
conductivity of plate. The heat transfer coefficients are evaluated at the corresponding fluid mean temperature in the PHEs.

The outlet temperatures of four PHEs are then obtained from the following effectiveness expression by using the effectiveness values given from Eq. (52),

$\varepsilon=\frac{C_{\mathrm{c}}\left(T_{\mathrm{c}, \text { out }}-T_{\mathrm{c} \text { in }}\right)}{C_{\text {min }}\left(T_{\mathrm{h}, \text { in }}-T_{\mathrm{c}, \text { in }}\right)}=\frac{C_{\mathrm{h}}\left(T_{\mathrm{h}, \text { in }}-T_{\mathrm{h}, \text { out }}\right)}{C_{\min }\left(T_{\mathrm{h}, \text { in }}-T_{\mathrm{c}, \text { in }}\right)}$

The total heat transfer area of the PHE may be calculated based on the maximum heat load required in the solar-thermal and HR systems. For instance, its area in the solar-thermal system can be determined in accordance with the heat generated at the maximum irradiance, i.e., $G_{\mathrm{T}, \max }=940 \mathrm{~W} / \mathrm{m}^{2}$ at noon in April, on the ETCs, the equation of which is defined as $A_{\mathrm{HX}}=G_{\mathrm{T}, \max } \eta_{0} A_{\mathrm{c}} / U_{\mathrm{HX}} \mathrm{LMTD}$. It can be obtained by the iterative procedure, which is repeated by guessing the values of the overall heat transfer coefficient until the difference between the guessed and calculated values is less than a predetermined value of $10^{-10}$.

The total pressure drop for each stream through the PHE can be estimated as the sum of channel and port pressure drop correlations, $\Delta P_{\mathrm{ch}}$ and $\Delta P_{\mathrm{pt}}$, and are given as [52]:

$\Delta P_{\mathrm{PHE}}=\frac{4 f_{\mathrm{ch}} N_{\mathrm{pass}} L_{\mathrm{h}} G_{\mathrm{ch}}^{2}}{2 \rho D_{\mathrm{e}}}+1.3 N_{\mathrm{pass}} \frac{G_{\mathrm{pt}}^{2}}{2 \rho}$

with the Fanning-type friction factors, $f_{\mathrm{ch}}=K_{\mathrm{p}} / \boldsymbol{R} \boldsymbol{e}^{m}$, that are related to single-phase friction loss inside tubes, and $K_{\mathrm{p}}$ and $m$ are constant versus $R e$ for various chevron angles [52]. Here, the viscosity correction factor in the term of pressure drop through the channels is neglected.

\subsection{Solution procedure}

The solution process has been carried out on the basis of a global algorithm that solves in a segregated manner the governing equations: (i) for the collector outlet temperature, i.e., Eq. (32), (ii) for the seawater storage tanks, i.e., Eq. (34) with the boundary conditions Eqs. (35) and (36), (iii) for the brine and permeate storage tanks, i.e., Eq. (47) with the boundary conditions Eqs. (48) and (49) and (iv) for the outlet temperatures of the PHE in the solar-thermal system and the brine- and permeate-heatrecovery PHEs, i.e., Eq. (52). A standard tridiagonal matrix algorithm (TDMA) with a successive line under-relaxation method is used to solve the Eqs. (34) and (47), while a shooting method is used to solve Eqs. (32) and (52). The iterative approach is implemented to ensure the coupling between the four main subroutines. The iterative procedure continues until the convergence criterion is satisfied at each time step, i.e., $\left|s^{m+1}-s^{m}\right|<10^{-4}$, where $s$ is any variable temperature and $m$ is the iteration level. For a stable solution and grid independent results, the values used for the time and space step sizes are: $\Delta t=150 \mathrm{sec}$ and $\Delta h=0.1 \mathrm{~m}$. All of the governing equations are solved numerically by developing a source code written in Microsoft Fortran PowerStation 4.0.

\section{Results and discussion}

3.1 Hollow fiber DCMD 


\subsubsection{Spatial variation}

The baseline DCMD module parameters and operating conditions listed in Tables 2 are used to predict the performance of the hollow fiber module using the developed model equations for both tube and shell side flows. The velocity variations along the fiber length for both retentate (feed) and permeate flows are plotted in Fig. 6 . The feed side velocity $\left(v_{\mathrm{f}}\right)$ decreases from the inlet $0.472 \mathrm{~m} / \mathrm{s}$ to the outlet $0.442 \mathrm{~m} / \mathrm{s}$, while the permeate side velocity $\left(v_{\mathrm{p}}\right)$ increases from the inlet $0.343 \mathrm{~m} / \mathrm{s}$ to the outlet $0.368 \mathrm{~m} / \mathrm{s}$. It is shown that the velocity variation of $0.025 \mathrm{~m} / \mathrm{s}$ at the permeate side is relatively smaller than that of $0.03 \mathrm{~m} / \mathrm{s}$ at the feed side, which may be attributed to the larger cross-sectional area with a packing density of 59\%. Further, it is observed that at both feed and permeate sides the velocity gradient is steep at the front end of the module. This gradient, in the feed side flow, is steeper because of the larger transmembrane permeate flux, resulting from a higher transmembrane vapor pressure difference at the front end of the module.

Fig. 7 shows the pressure variations of the bulk feed $\left(P_{\mathrm{f}}\right)$, at the feed $\left(P_{\mathrm{f}, \mathrm{m}}\right)$ and permeate $\left(P_{\mathrm{p}, \mathrm{m}}\right)$ sides of membrane and the bulk permeate $\left(P_{\mathrm{p}}\right)$ along the fiber length. For the bulk liquid pressures, the inlet feed pressure is $137 \mathrm{kPa}$, while the inlet permeate pressure is $132 \mathrm{kPa}$, because both outlet pressures of feed and permeate are required to be the ambient atmospheric pressure. The axial hydrostatic pressure drop of $31 \mathrm{kPa}$ in the permeate side is relatively lower than that of $36 \mathrm{kPa}$ in the feed side, which is due to the countercurrent flow pattern, the cumulative permeate flux from the feed side to the permeate side as well as the relatively larger cross-sectional area at the permeate side with a packing density of $59 \%$. Because the driving force in DCMD is the vapor pressure difference between the two membrane sides (i.e., $P_{\mathrm{f}, \mathrm{m}}-P_{\mathrm{p}, \mathrm{m}}$ ), the transmembrane hydrostatic pressure has no influence on the mass flux. However, the applied transmembrane pressure, i.e., $P_{\mathrm{f}}-P_{\mathrm{f}, \mathrm{m}}$ and $P_{\mathrm{p}}-P_{\mathrm{p}, \mathrm{m}}$, must be lower than the membrane liquid entry pressure (i.e., breakthrough pressure, $L E P$ ) in order to prevent liquid solutions from entering its pores. According to the Franken et al. [53], the $L E P$ can be estimated from:

$$
\begin{gathered}
L E P=\frac{-2 B \gamma_{\mathrm{L}} \cos \theta}{r_{\text {max }}}>\Delta P_{\mathrm{f}, \mathrm{m}}\left(=P_{\mathrm{f}}-P_{\mathrm{f}, \mathrm{m}}\right) \\
L E P=\frac{-2 B \gamma_{\mathrm{L}} \cos \theta}{r_{\text {max }}}>\Delta P_{\mathrm{p}, \mathrm{m}}\left(=P_{\mathrm{p}}-P_{\mathrm{p}, \mathrm{m}}\right)
\end{gathered}
$$

where $B$ is a geometric pore coefficient ( $B=1$ for cylindrical pores), $\gamma_{\mathrm{L}}$ is the liquid surface tension, $\theta$ is the liquid-solid contact angle and $r_{\max }$ is the maximum pore size. For a typical PVDF membrane contact angle of $130^{\circ}$ and a maximum pore diameter of $1 \mu \mathrm{m}$ [29], the $L E P$ of the hydrophobic membrane used in this study is about $185 \mathrm{kPa}$. The maximum pressure difference at the interface of the feed side, $\Delta P_{\mathrm{f}, \mathrm{m}}$, is about $108 \mathrm{kPa}$, whereas at the interface of the feed side the maximum pressure difference, $\Delta P_{\mathrm{p}, \mathrm{m}}$, is 128 $\mathrm{kPa}$.

The variations in the temperatures of the bulk feed $\left(T_{\mathrm{f}}\right)$, at the feed $\left(T_{\mathrm{f}, \mathrm{m}}\right)$ and permeate $\left(T_{\mathrm{p}, \mathrm{m}}\right)$ sides of membrane and the bulk permeate $\left(T_{\mathrm{p}}\right)$ as a function of the fiber length are depicted in Fig. 8(a). It is shown that $T_{\mathrm{f}}$ decreases from the inlet $80^{\circ} \mathrm{C}$ to the outlet $39^{\circ} \mathrm{C}$ and the transmembrane temperature $\left(T_{\mathrm{f}, \mathrm{m}}-\right.$ $\left.T_{\mathrm{p}, \mathrm{m}}\right)$ ranges from $3^{\circ} \mathrm{C}$ to $5^{\circ} \mathrm{C}$ along the fiber length, while $T_{\mathrm{p}}$ increases from the inlet $30^{\circ} \mathrm{C}$ to the outlet 
$66^{\circ} \mathrm{C}$, which is attributed to the heat transfer through the membrane in the form of both vapor latent heat and heat conduction. In general, the heat transfer at the boundary layer is recognized as the limiting factor of the transport efficiency and the temperature polarization coefficient has been widely used as an index to quantify the magnitude of the boundary layer resistances over the total heat transfer resistance. Khayet et al. [54] proved an asymmetric polarization phenomenon in DCMD process and observed that the temperature polarization in the feed side is higher than that in the permeate side. The local overall temperature polarization coefficient $(T P C)$ is defined as follows:

$T P C=T P C_{\mathrm{f}}+T P C_{\mathrm{p}}-1$

where $T P C_{\mathrm{f}}$ and $T P C_{\mathrm{P}}$ are the temperature polarization coefficients corresponding to the feed and permeate phases, respectively, and are given by

$T P C_{\mathrm{f}}=\frac{T_{\mathrm{f}, \mathrm{m}}-T_{\mathrm{p}}}{T_{\mathrm{f}}-T_{\mathrm{p}}}, \quad T P C_{\mathrm{p}}=\frac{T_{\mathrm{f}}-T_{\mathrm{p}, \mathrm{m}}}{T_{\mathrm{f}}-T_{\mathrm{p}}}$

From Eq. (55), the global TPC (GTPC) corresponding to the membrane module can be calculated using a procedure analogous to Eqs. (23) and (24) [55]:

$G T P C=\frac{1}{L_{\mathrm{f}}} \int_{0}^{L_{\mathrm{f}}} T P C(z) d z=\frac{1}{L_{\mathrm{f}}} \int_{0}^{L_{\mathrm{f}}} \frac{T_{\mathrm{f}, \mathrm{m}}(z)-T_{\mathrm{p}, \mathrm{m}}(z)}{T_{\mathrm{f}}(z)-T_{\mathrm{p}}(z)} d z$

As can be observed in Fig. 8(b), the values of the temperature polarization coefficients, $T P C_{\mathrm{f}}, T P C_{\mathrm{p}}$ and $T P C$, increase asymptotically along the fiber length. It is noted that the mean value of $T P C_{\mathrm{f}}$ along the fiber length is about $23 \%$ higher than that of $T P C_{\mathrm{p}}$ and the mean value of $T P C$, i.e., $G T P C$ is about $42 \%$ and $29 \%$ lower than those of $T P C_{\mathrm{f}}$ and $T P C_{\mathrm{p}}$, respectively [53]. The value of GTPC obtained from Eq. (57) is 0.47 . This indicates that $53 \%$ of the applied temperature difference is dissipated in both the feed and the permeate boundary layers.

Fig. 9 shows the variation of permeate flux and performance ratio along the fiber length. The transmembrane flux decreases significantly from 46 to $2.7 \mathrm{~kg} / \mathrm{m}^{2} \mathrm{~h}$ corresponding to the temperature difference across the membrane of $3^{\circ} \mathrm{C}$ and $5^{\circ} \mathrm{C}$ at the inlet and outlet of the module, respectively. On the other hand, the thermal efficiency decreases from 0.87 to 0.2 along the fiber length due to the reduction in the vaporization heat associated with the transmembrane flux.

The variation of salt concentration in the feed side as a function of the fiber length is presented in Fig. 10. It is shown that the salt concentration increases asymptotically from $45 \mathrm{~g} / \mathrm{kg}$ to $48 \mathrm{~g} / \mathrm{kg}$, which is attributed to an asymptotic decrease of the transmembrane flux along the fiber length as shown in Fig. 9. In the once-through feed DCMD process studied, the water recovery ratio, defined as the ratio of distillate production to feed flow, is quite smaller at the value of about $7 \%[14,56,57]$, as compared to the overall water recovery of brine recirculation DCMD process [57]. Here, the brine recirculation DCMD system has an advantage of lower brine discharges from increased water recovery mainly due to the independence of driving force on the salinity [58], but it can be expected that the permeate flux decline associated with fouling and scaling phenomena may be more significant than the once-through feed system [59]. As expected from the smaller water recovery in the system studied, a higher pumping energy for seawater feed will be required, but some of it can be compensated by recovering the energy from the 
brine using the HR system implemented in this study.

\subsubsection{Effect of inlet temperatures}

The effect of inlet temperatures at both feed $\left(50 \leq T_{\mathrm{f}, \text { in }}\left({ }^{\circ} \mathrm{C}\right) \leq 90\right)$ and permeate $\left(20 \leq T_{\mathrm{p}, \text { in }}\left({ }^{\circ} \mathrm{C}\right) \leq 48\right)$ sides on the transmembrane pressures at both sides, $\Delta P_{\mathrm{f}, \mathrm{m}}$ and $\Delta P_{\mathrm{p}, \mathrm{m}}$, mean permeate flux $\left(J_{\mathrm{m}}\right)$ and performance ratio $(P R)$ are investigated at the inlet flow rates on both sides of $61 / \mathrm{min}$, based on the DCMD module parameters in Table 2.

As shown in Fig. 11(a) and (b), both $\Delta P_{\mathrm{f}, \mathrm{m}}$ and $\Delta P_{\mathrm{p}, \mathrm{m}}$ increase greatly with a decrease in both $T_{\mathrm{f}, \text { in }}$ and $T_{\mathrm{p}, \mathrm{in}}$, whereas these decrease with an increase in both $T_{\mathrm{f}, \mathrm{in}}$ and $T_{\mathrm{p}, \mathrm{in}}$. The maximum value of $\Delta P_{\mathrm{f}, \mathrm{m}}$ and $\Delta P_{\mathrm{p}, \mathrm{m}}$ is about $140 \mathrm{kPa}$ at $T_{\mathrm{f}, \mathrm{in}}=50^{\circ} \mathrm{C}$ and $T_{\mathrm{p}, \mathrm{in}}=20^{\circ} \mathrm{C}$, while these minimum values are $92 \mathrm{kPa}$ and 114 $\mathrm{kPa}$ at $T_{\mathrm{f}, \mathrm{in}}=90^{\circ} \mathrm{C}$ and $T_{\mathrm{p}, \mathrm{in}}=48^{\circ} \mathrm{C}$, respectively. It is shown that the effect of both feed and permeate inlet temperatures on both transmembrane pressures is quite small and thus the transmembrane pressures obtained at the given temperature conditions do not exceed the LEP (185 kPa). Fig. 11(c) shows that $J_{\mathrm{m}}$ increases exponentially with increasing $T_{\mathrm{f}, \mathrm{in}}$ at fixed $T_{\mathrm{p}, \mathrm{in}}$, as a consequence of the significant increase in the driving force $[1,6,7,14,32,56]$, which can be predicted by the Antoine equation given in Eq. (12). As shown in Fig. 11(d), $P R$ also increases gradually with $T_{\mathrm{f}, \mathrm{in}}$ since the vaporization heat is greater than the heat loss by conduction through the membrane when $T_{\mathrm{f}, \text { in }}$ increases [1]. In contrast, $J_{\mathrm{m}}$ decreases slightly with an increase in $T_{\mathrm{p}, \mathrm{in}}$ at fixed $T_{\mathrm{f}, \mathrm{in}}$, while $P R$ increases gradually. Hence, it is shown that there is a tradeoff between $J_{\mathrm{m}}$ and $P R$ with respect to $T_{\mathrm{p}, \text { in }}$ when $T_{\mathrm{f}, \text { in }}$ is kept constant.

As can be expected from Fig. 11(c), $T_{\mathrm{f}, \mathrm{in}}$ has a significant influence on $J_{\mathrm{m}}$ than $T_{\mathrm{p}, \mathrm{in}}$. The maxima of $J_{\mathrm{m}}$ and $P R$ are obtained at the highest $T_{\mathrm{f}, \mathrm{in}}$ [1] in the range studied due to the exponential increase of the partial vapor pressure with $T_{\mathrm{f} \text {,in }}$ and these values are $23.54 \mathrm{~kg} / \mathrm{m}^{2} \mathrm{~h}$ at $T_{\mathrm{f} \text {,in }}=90^{\circ} \mathrm{C}$ and $T_{\mathrm{p} \text {,in }}=20^{\circ} \mathrm{C}$ and 0.75 at $T_{\mathrm{f}, \text { in }}=90^{\circ} \mathrm{C}$ and $T_{\mathrm{p}, \text { in }}=48^{\circ} \mathrm{C}$, respectively.

\subsubsection{Effect of inlet flow rates}

The transmembrane flux and performance ratio can be enhanced by increasing the feed flow rate, which resulting in improving the hydrodynamic conditions in terms of Reynolds number, heat and mass transfer coefficients $[1,2,6,7,14,32,54]$. On the other hand, increasing the flow rates of both feed and permeate sides can lead to the membrane pore wetting due to the hydrostatic pressure build-up and the higher pressure drop along the membrane module as well as the higher pumping power [2,32]. Here, the effect of inlet flow rates $\left(3 \leq V_{\text {f,in }}\right.$ and $\left.V_{\text {p,in }}(1 / \mathrm{min}) \leq 20\right)$ of both feed and permeate sides on the transmembrane pressures at both sides, mean permeate flux and performance ratio are examined by keeping the inlet temperatures at feed and permeate sides constant at $80^{\circ} \mathrm{C}$ and $30^{\circ} \mathrm{C}$, respectively, based on the DCMD module parameters in Table 2.

As shown in Fig. 12(a), as both $V_{\mathrm{f}, \text { in }}$ and $V_{\mathrm{p}, \mathrm{in}}$ increases, $\Delta P_{\mathrm{f}, \mathrm{m}}$ increases significantly up to $176 \mathrm{kPa}$ at both flow rates of $20 \mathrm{l} / \mathrm{min}$, but the maximum value does not exceed the $L E P$. At higher $V_{\text {p,in }}$ above 14 $1 /$ min, however, it causes $\Delta P_{\mathrm{p}, \mathrm{m}}$ to exceed the $L E P$ regardless of $V_{\mathrm{f}, \mathrm{n}}$, as presented in Fig. 12(b). It is shown that the maximum $\Delta P_{\mathrm{p}, \mathrm{m}}$ occurs mainly at the inlet region of the permeate. Fig. 12(c) shows that at relatively lower $V_{\mathrm{p} \text {,in }}$ below $8 \mathrm{l} / \mathrm{min} J_{\mathrm{m}}$ increases with increasing $V_{\mathrm{f} \text {,in }}$ but the slopes gradually decrease at 
higher $V_{\mathrm{f} \text {,in }}$, whereas $J_{\mathrm{m}}$ increases linearly as $V_{\mathrm{f} \text {,in }}$ increases at higher $V_{\mathrm{p}, \mathrm{in}}$. As $V_{\mathrm{f} \text {,in }}$ increases at fixed $V_{\mathrm{p}, \mathrm{in}}$, $P R$ increases gradually, as shown in Fig. 12(d). Therefore, a higher feed flow rate can increase the heat transfer coefficient and then reduce the temperature and concentration polarization effects with a shorter residence time of the hot feed within the hollow fiber module, which results in increase of the driving force, yielding the higher $J_{\mathrm{m}}$ and $P R[1,2,6,7,14,32,54]$.

On the other hand, $J_{\mathrm{m}}$ increases greatly followed by a slight decrease as $V_{\mathrm{p}, \mathrm{in}}$ further increases at fixed $V_{\mathrm{f}, \mathrm{in}}$, especially at higher $V_{\mathrm{f} \text {,in }}$. Therefore, $J_{\mathrm{m}}$ at each $V_{\mathrm{f} \text {,in }}$ has a maximum value at certain value of $V_{\mathrm{p}, \mathrm{in}}$, and the value of $V_{\mathrm{p} \text {,in }}$ having a maximum value for $J_{\mathrm{m}}$ increases with an increase in $V_{\mathrm{f} \text {,in }}$. This may be explained as follows. If the feed flow rate is much higher than the permeate flow rate, more permeate flux occurs near the inlet of the permeate, and the driving force may be decrease significantly along the fiber length due to a substantial heat up of the permeate. On the contrary, more permeate flux occurs near the inlet of the feed when the feed flow rate is much lower than the permeate flow rate. As shown in Fig. 12(d), however, $P R$ increases gradually as $V_{\mathrm{p} \text {,in }}$ decreases at fixed $V_{\mathrm{f}, \mathrm{in}}$, showing a trade-off between $J_{\mathrm{m}}$ and $P R$ with respect to $V_{\mathrm{p} \text {,in }}$. This is because the vaporization heat associated with the transmembrane flux becomes greater than the heat loss by conducting through the membrane at relatively lower permeate flow rate.

It is also shown that $V_{\mathrm{f}, \mathrm{in}}$ has a greater effect on $J_{\mathrm{m}}$ than $V_{\mathrm{p} \text {,in. }}$. Under the operating conditions without membrane pore wetting, the maxima of $J_{\mathrm{m}}$ and $P R$ are obtained at the highest $V_{\mathrm{f}, \mathrm{in}}[1]$ in the range studied and these values are about $39 \mathrm{~kg} / \mathrm{m}^{2} \mathrm{~h}$ at $V_{\mathrm{f}, \text { in }}=201 / \mathrm{min}$ and $V_{\mathrm{p} \text {,in }}=141 / \mathrm{min}$ and 0.82 at $V_{\mathrm{f}, \text { in }}=201 / \mathrm{min}$ and $V_{\mathrm{p}, \mathrm{in}}=4 \mathrm{l} / \mathrm{min}$, respectively.

\subsubsection{Effect of fiber dimensions}

The effect of fiber dimensions on the transmembrane pressures at both sides, mean permeate flux, performance ratio and total distillate production $(T P D)$ of the hollow fiber DCMD module is investigated with respect to fiber length $\left(0.2 \leq L_{\mathrm{f}}(\mathrm{m}) \leq 1.0\right)$ and packing density $(0.2 \leq \phi \leq 0.8)$, with the inlet flow rates at both sides of $61 / \mathrm{min}$ and inlet feed and permeate temperatures of $80^{\circ} \mathrm{C}$ and $30^{\circ} \mathrm{C}$.

As depicted in Fig. 13(a) and (b), $\Delta P_{\mathrm{f}, \mathrm{m}}$ does exceed the $L E P$ at higher $L_{\mathrm{f}}$ above $0.6 \mathrm{~m}$ and lower $\phi$ below 0.4 , while a higher $\phi$ above 0.63 causes $\Delta P_{\mathrm{p}, \mathrm{m}}$ to exceed the $L E P$ regardless of $L_{\mathrm{f}}$. The results shown in Fig. 13(c) reveal that $J_{\mathrm{m}}$ decreases with increasing $\phi$ at fixed $L_{\mathrm{f}}$, which is consistent with the experimental results [25,32,60-62]. A dramatic decrease in $J_{\mathrm{m}}$ is observed when $\phi$ increases in the lower $\phi$ range (20-40\%) [61], especially at the lower $L_{\mathrm{f}}$ range. Furthermore, a higher $\phi$ decreases $P R$ since the reduction in the vaporization heat due to flux decline occurring at higher $\phi$ is more significant than the decrease in the heat conduction through the membrane, as shown in Fig. 13(d).

Both $J_{\mathrm{m}}$ and $P R$ also decrease with the increase of $L_{\mathrm{f}}$ at a constant value of $\phi$. It is clearly shown that $J_{\mathrm{m}}$ decreases dramatically with increasing $L_{\mathrm{f}}$ in the beginning, and then gradually reaches its asymptotic value at a higher $L_{\mathrm{f}}$. This is because with an increase in $L_{\mathrm{f}}$ the local transfer resistance increases greatly due to the rapid build-up of thermal boundary layers which reduces the temperature difference through the membrane and hinders the mass and heat transfer [61]. In addition, the reduction of $J_{\mathrm{m}}$ is found to be 
attributed to the extremely low temperature gradient across the membrane due to the longer retention time of the stream with an increase in $L_{\mathrm{f}}$. Therefore, it is important to identify the fiber length to assure that the driving force along the fiber is sufficient to maintain a high performance ratio, even though a longer fiber length and thus a larger membrane area can result in higher TPD of the module $[32,61,63]$. As can be seen in Fig. 13(c), the influence of $L_{\mathrm{f}}$ on $J_{\mathrm{m}}$ is more greater than that of $\phi$.

In contrast, TPD increases with increasing both $L_{\mathrm{f}}$ and $\phi$, while at higher $L_{\mathrm{f}}$ and $\phi$ its increment is negligibly small, as shown in Fig. 14. Hence, it indicates that there is a trade-off between TPD and PR with respect to $\phi$ while keeping $L_{\mathrm{f}}$ constant. The maxima of $J_{\mathrm{m}}$ and $P R$ are obtained at the lowest $\phi$ [61] in the range studied and these values are $51.14 \mathrm{~kg} / \mathrm{m}^{2} \mathrm{~h}$ at $L_{\mathrm{f}}=0.2 \mathrm{~m}$ and $\phi=0.2$ and 0.74 at $L_{\mathrm{f}}=0.25 \mathrm{~m}$ and $\phi=0.2$, respectively, while the maximum $T P D$ is $27.39 \mathrm{~kg} / \mathrm{h}$ at $L_{\mathrm{f}}=1.0 \mathrm{~m}$ and $\phi=0.6$.

\subsection{Solar-assisted DCMD desalination system}

The plant parameters and input data of solar-assisted DCMD system are given in Table 3. Single collector array in series arrangement is adapted for low pressure drop and high collector efficiency purposes. Based on the baseline DCMD module parameters and operating conditions listed in Tables 2 and 3, the long-term thermal and performance analyses of solar-assisted DCMD system are carried out with respect to collector area $A_{\mathrm{c}}$ in the range of $1983 \mathrm{~m}^{2}-3360 \mathrm{~m}^{2}$ and seawater storage volume $V_{\mathrm{st}}$ in the range of $80 \mathrm{~m}^{3}-260 \mathrm{~m}^{3}$ at the ASHRAE standard flow rate. The desalination system comprises the solarthermal system with TM unit, the HR unit and the shell-and-tube type DCMD modules. The system performances are reported in terms of the annual solar fraction, $S F$, and collector efficiency, $S E$. The solar-assisted desalination system with 50 shell-and-tube type DCMD modules has the overall permeate production capacity of $31 \mathrm{~m}^{3} /$ day.

Fig. 15 represents the mean temperature profiles of four storage tanks and instantaneous efficiency, $S F$ and $S E$, of solar collector over the three days from $14^{\text {th }}$ to $15^{\text {th }}$ January with respect to $A_{\mathrm{c}}$ with $V_{\mathrm{t}}=160$ $\mathrm{m}^{3}$. Here, the mean temperature of the seawater storage tank $i$ is calculated as,

$T_{\mathrm{st}, i}^{\mathrm{m}}=\frac{\sum_{j=1}^{N_{\mathrm{T}}} \rho_{i, j} V_{\mathrm{st}, i, j} T_{\mathrm{st}, i, j}}{\sum_{j=1}^{N_{\mathrm{T}}} \rho_{i, j} V_{\mathrm{st}, i, j}}$

As shown in Fig. 15(a), when $A_{\mathrm{c}}$ and $V_{\mathrm{st}}$ are $1983 \mathrm{~m}^{2}$ and $160 \mathrm{~m}^{3}$, the storage temperatures increase from about 8:30 am with increasing solar energy incident on the collector, and then the storage tank-4 temperature decrease gradually until about 8:20 pm after attaining a maximum value of $73^{\circ} \mathrm{C}$ at about 3:30 pm followed by a significant decrease without solar energy input as time further elapses until 3:30 am next day. The effect of storage temperature is reflected on the instantaneous $S F$ and $S E$ having the maximum values of 0.75 and 0.63 , respectively. It is shown that the annual $S F$ and $S E$ are $48 \%$ and $56 \%$, respectively. It is noted that this qualitative trend is also upheld by the systems with different collector areas, i.e., $2439 \mathrm{~m}^{2}, 2898 \mathrm{~m}^{2}$ and $3360 \mathrm{~m}^{2}$, as illustrated in Fig. 15(b), (c) and (d), respectively. In particular, for the systems with higher $A_{\mathrm{c}} \mathrm{s}$ above $2898 \mathrm{~m}^{2}$ shown in Fig. 15(c) and (d), the seawater 
storage temperatures exceed the set feed temperature to the DCMD modules of $80^{\circ} \mathrm{C}$ at 2:05 pm and 1:14 $\mathrm{pm}$, respectively, but the supply seawater drawn from storage tank-4 is mixed with the makeup seawater to attain the desired feed temperature by means of TM unit. This arrangement enables some of high stored energy during the midday hours to be used for the late-afternoon and night-time hours. Therefore, these systems can fulfill the feed demand and last until 10:40 pm and 1:07 am next day.

However, an increase of storage temperature in the system with the TM unit may results in higher heat losses from the storage tanks and lower collector efficiency, as compared to the system without it, but its effects are not crucial to the thermal performance of the system. This is because an increase in the annual $S F$ of the system with TM unit is much greater than a decrease in the annual $S E$, compared to that of the system without it [44]. It is shown that as $A_{\mathrm{c}}$ increases from $2439 \mathrm{~m}^{2}$ to $3360 \mathrm{~m}^{2}$ the annual $S F$ are $58 \%$, $68 \%$ and $77 \%$, respectively, while the annual $S E$ are $55 \%, 54 \%$ and $53 \%$, respectively.

Fig. 16 shows the annual $S F$ and $S E$ of the system with respect to $A_{\mathrm{c}}$ in the range of $2439 \mathrm{~m}^{2}-3360$ $\mathrm{m}^{2}$ and $V_{\mathrm{st}}$ in the range of $80 \mathrm{~m}^{3}-260 \mathrm{~m}^{3}$. The annual $S F$ increases slightly, i.e., from $57 \%$ to $59 \%$ for $A_{\mathrm{c}}$ $=2439 \mathrm{~m}^{2}$, from $67 \%$ to $70 \%$ for $A_{\mathrm{c}}=2898 \mathrm{~m}^{2}$ and from $77 \%$ to $80 \%$ for $A_{\mathrm{c}}=3360 \mathrm{~m}^{2}$, with an increase in $V_{\mathrm{st}}$ at each $A_{\mathrm{c}}$, as shown in Fig. 16(a). It is because with an increase in $V_{\mathrm{st}}$ the rate of the removed energy from the tank to supply the feed seawater increases and the required auxiliary energy decreases, compared to an increase in heat losses from the storage tank with increasing $V_{\mathrm{st}}$. As shown in Fig. 16(b), the annual $S E$ also increases asymptotically, i.e., from $53 \%$ to $57 \%$ for $A_{\mathrm{c}}=2439 \mathrm{~m}^{2}$, from $53 \%$ to $56 \%$ for $A_{\mathrm{c}}=2898 \mathrm{~m}^{2}$ and from $53 \%$ to $55 \%$ for $A_{\mathrm{c}}=3360 \mathrm{~m}^{2}$, with increasing $V_{\mathrm{st}}$, which is attributed to decrease in storage tank temperature that reduces the collector efficiency. For $V_{\mathrm{st}}=160 \mathrm{~m}^{3}$ the annual $S F$ is found to linearly increase as $A_{\mathrm{c}}$ increases from $1983 \mathrm{~m}^{2}$ to $3360 \mathrm{~m}^{2}$, whereas the annual $S E$ decreases linearly with increasing $A_{\mathrm{c}}$, as shown in Fig. 17. The linear correlations of annual $S F$ and $S E$ vs. $A_{\mathrm{c}}$ within these $A_{\mathrm{c}}$ ranges are as follows:

$$
\begin{aligned}
& S F=2.069 \times 10^{-4} A_{\mathrm{c}}+0.076 \\
& S E=-2.691 \times 10^{-5} A_{\mathrm{c}}+0.616
\end{aligned}
$$

The implementation of HR unit on the $31 \mathrm{~m}^{3} /$ day DCMD desalination system decreases significantly the overall specific thermal energy consumption (OSTEC) by recovering the heat from the brine and permeate streams to preheat the feed. The OSTEC of DCMD system without HR unit is $771 \mathrm{kWh} / \mathrm{m}^{3}$, whereas its value with HR is $436 \mathrm{kWh} / \mathrm{m}^{3}$ and is about $43 \%$ lower than that of DCMD system without HR. A simple theoretical evaluation for predicting the specific energy consumption both thermal (i.e., auxiliary) and electrical energy per $\mathrm{m}^{3}$ of distillate produced is then performed for a solar-assisted DCMD desalination system with various collector areas and a storage tank volume of $160 \mathrm{~m}^{3}$. A summary of the specific thermal and electrical energy consumptions, STEC and SEEC, in accordance with collector area for DCMD system with HR and TM units is presented in Table 4. The STEC can be expressed in terms of $S F$ and OSTEC of DCMD system with HR and is given by

$$
S T E C=O S T E C \times(1-S F)
$$

When $A_{\mathrm{c}}$ increases from $1983 \mathrm{~m}^{2}$ to $3360 \mathrm{~m}^{2}$, the $S T E C$ decreases greatly by $55 \%$ due to an increase in $S F$, while the $S E E C$ increases slightly by $16 \%$ because of an increased volume flow rate in primary solar 
circuit resulting in a higher pumping energy. Fig. 18 represents the STEC of DCMD system with respect to $A_{\mathrm{c}}$ and $V_{\mathrm{st}}$. Regardless of $A_{\mathrm{c}}$, the higher seawater storage volume results in the reduction of STEC. The effect of $V_{\mathrm{st}}$ on the STEC becomes significant at higher $A_{\mathrm{c}}$ [44]: for instance, it declines by $2.7 \%, 5.9 \%$, $7.5 \%$ and $13.2 \%$ for each $A_{\mathrm{c}}$, respectively, with increasing $V_{\mathrm{st}}$ in the feasible operating regions. It is because with increasing $A_{\mathrm{c}}$ and $V_{\mathrm{st}}$ the rate of the removed energy from the storage tank to supply the load increases and the required auxiliary energy decrease greatly, as compared to the increase in heat losses from the storage tank with an increase in $V_{\text {st }}$.

Therefore, the aforementioned results reinforce the notion that the solar-assisted DCMD for a continuous 24-hour-a-day operation is still high-energy consuming process as compared to the conventional distillation processes [14,56], even though MD requires lower operating temperatures than the conventional ones. Furthermore, as can be also seen from the previous studies [2], the heat loss by conduction through the membrane matrix in DCMD configuration studied is considerably high, so that it should be minimized in order to diminish the temperature polarization effect and enhance the efficiency of the DCMD process. This heat loss may be minimized by using high porosity hydrophobic membranes with an appropriate thickness, made of low heat conductivity polymers [1].

\section{Conclusions}

The long-term performance of a solar-assisted hollow fiber DCMD desalination system with the heat recovery scheme is evaluated with a rigorous mathematical model for each component in the system. A temperature modulating scheme is further implemented in the solar-thermal system to achieve prolonged operating hours with preferred temperature range and thus improve the efficacy of the system.

It is illustrated that there are trade-off between mean permeate flux and performance ratio with respect to permeate inlet temperature and flow rate while keeping feed inlet temperature and flow rate constant, respectively, and between total distillate production and performance ratio with respect to packing density at a constant fiber length. It is also found that the most significant factor effecting the mean permeate flux over the operating range studied is the module dimensions, especially fiber length. At the hot feed and cold permeate flow rates of $61 / \mathrm{min}$ and the hot and cold temperatures of $80^{\circ} \mathrm{C}$ and $30^{\circ} \mathrm{C}$, the maximum mean permeate flux is about $51.14 \mathrm{~kg} / \mathrm{m}^{2} \mathrm{~h}$ at fiber length of $0.2 \mathrm{~m}$ and packing density of $20 \%$, and the maximum performance ratio is about 0.74 at fiber length of $0.25 \mathrm{~m}$ and packing density of $20 \%$. For the solar-assisted DCMD desalination system having $3360 \mathrm{~m}^{2}$ of evacuated-tube collectors with $160 \mathrm{~m}^{3}$ seawater storage tanks and 50 DCMD modules, the annual solar fraction and collector efficiency are found to be 0.77 and 0.53 , respectively whilst the overall permeate production capacity is $31 \mathrm{~m}^{3} / \mathrm{day}$. The overall specific thermal energy consumption of solar-assisted DCMD system with heat recovery is found to be $436 \mathrm{kWh} / \mathrm{m}^{3}$ and it is about $43 \%$ lower than that of DCMD system without heat recovery. It is noted that with an increase in collector area from $1983 \mathrm{~m}^{2}$ to $3360 \mathrm{~m}^{2}$ the specific thermal energy consumption decreases by $55 \%$, whereas the specific electrical energy consumption increases by $16 \%$. Regardless of collector area, the higher seawater storage volume results in the reduction of specific thermal energy consumption, especially at higher collector area.

As expected, the solar-assisted DCMD for a large-scale, stand-alone desalination plant with 
continuous 24-hour-a-day operation is still energy intensive and expensive process as compared to the other desalination systems. With developing high porosity hydrophobic membranes with low heat conductivity and appropriate thickness for flux enhancement and heat-loss reduction, however, DCMD may have a high potential for the large-scale, stand-alone desalination plants with continuous 24-hour-aday operation and the integration with large seawater RO desalination plants (such as MF/NF/RO) to be operated in the brine stream, if the utilization of low-grade waste heat from industrial processes is available. Besides, DCMD desalination system combining solar and geothermal energy with an alternating 12-hour cycle may eliminate the need for heat storage, reduce the probability of depleting the heat source in geothermal reservoirs, reduce significantly the carbon footprint of desalination and provide the most effective use of renewable energy. Furthermore, with increasing the reliability of the DCMD technology and plant lifetime, solar-powered DCMD plant is able to provide potable water for the remote areas with low infrastructure as a small-scale, stand-alone system with low maintenance requirements. Therefore, more design and development effort on the configuration, module and system as well as membrane should be required for improving the MD performance and looking for MD industrialization. The verification of models based on experimental data and economical evaluation to assess the feasibility of MD as desalination plant will be reported in our future research.

\section{Nomenclature}

A membrane area ratio for heat transfer through fiber inside, fiber wall and fiber outside

$A_{\mathrm{a}} \quad$ aperture area per collector $\left(\mathrm{m}^{2}\right)$

$A_{\mathrm{c}} \quad$ total collector area $\left(\mathrm{m}^{2}\right)$

$A_{\text {ch }} \quad$ channel cross-sectional area, $b L_{\mathrm{w}}\left(\mathrm{m}^{2}\right)$

$A_{\mathrm{cs}} \quad$ cross sectional area of storage tank $\left(\mathrm{m}^{2}\right)$

$A_{\text {eff }} \quad$ effective area of plate, $L_{\mathrm{h}} L_{\mathrm{w}}\left(\mathrm{m}^{2}\right)$

$A_{\mathrm{HX}} \quad$ total heat transfer area of the plate heat exchanger $\left(\mathrm{m}^{2}\right)$

$A_{\mathrm{i}} \quad$ anisotropy index

$A_{1} \quad$ lateral area of control volume $\left(\mathrm{m}^{2}\right)$

$A_{\mathrm{pt}} \quad$ port cross-sectional area $\left(\mathrm{m}^{2}\right)$

$b \quad$ mean flow channel gap, $p-t(\mathrm{~m})$

$B \quad$ geometric factor

c concentration of all solutes $\left(\mathrm{mole} / \mathrm{m}^{3}\right)$

$c_{1} \quad$ global heat loss coefficient $\left(\mathrm{W} / \mathrm{m}^{2 \mathrm{o}} \mathrm{C}\right)$

$c_{2} \quad$ temperature dependence of global heat loss coefficient $\left(\mathrm{W} / \mathrm{m}^{2 \mathrm{o}} \mathrm{C}^{2}\right)$

$c_{3} \quad$ effective thermal capacity $\left(\mathrm{kJ} / \mathrm{m}^{2 \mathrm{o}} \mathrm{C}\right)$

$c_{\mathrm{p}} \quad$ specific heat capacity $\left(\mathrm{kJ} / \mathrm{kg}^{\circ} \mathrm{C}\right)$

$C \quad$ membrane distillation coefficient $\left(\mathrm{kg} / \mathrm{m}^{2} \mathrm{sPa}\right)$

$C_{\mathrm{c}} \quad$ fluid heat capacity rate in primary solar circuit $\left(\mathrm{W} /{ }^{\circ} \mathrm{C}\right)$

$C_{\mathrm{h}} \quad$ fluid heat capacity rate in secondary solar circuit $\left(\mathrm{W} /{ }^{\circ} \mathrm{C}\right)$

$C_{\mathrm{K}} \quad$ parameter in Knudsen diffusion efficient 


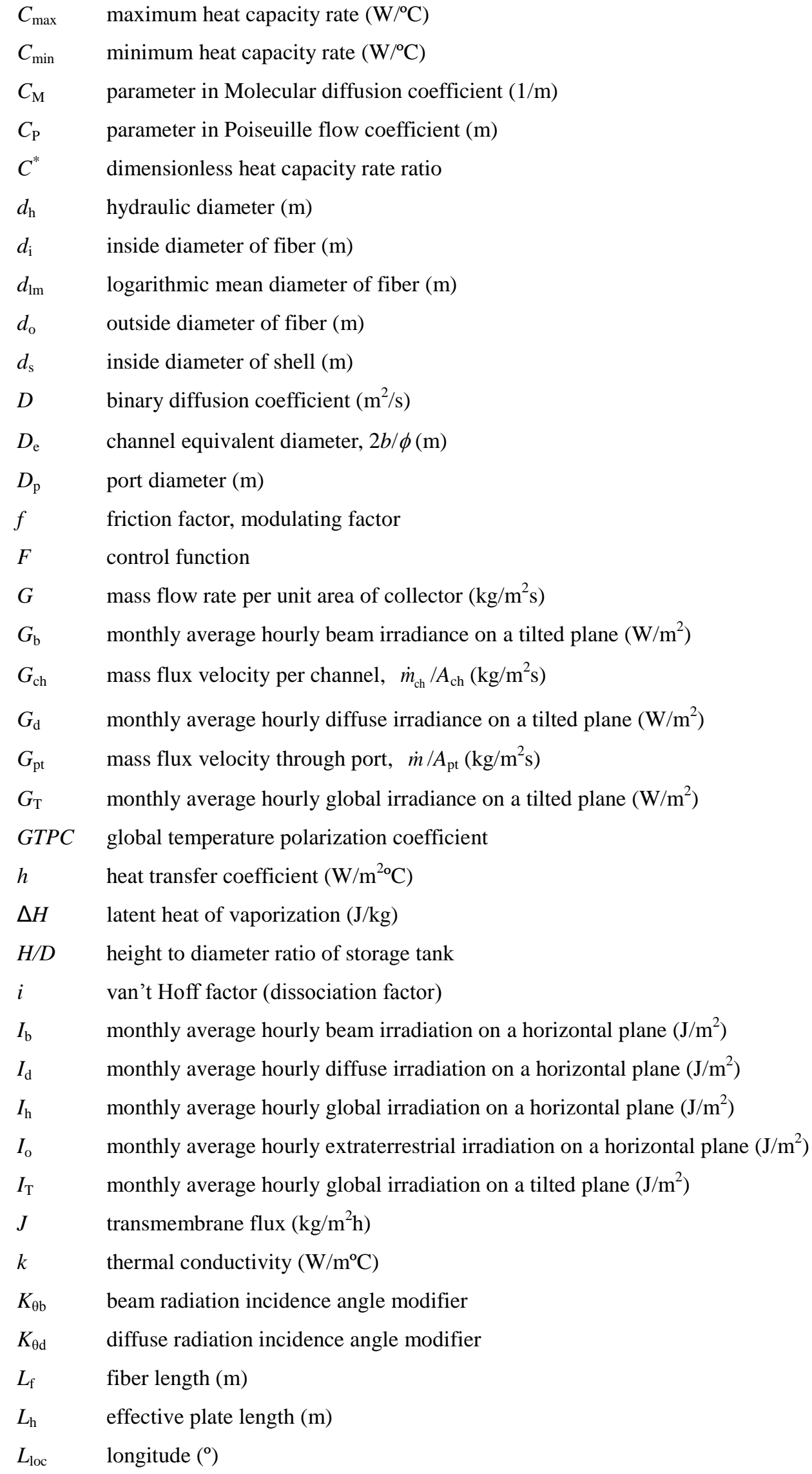


LEP liquid entry pressure $(\mathrm{Pa})$

LMTD logarithmic mean temperature difference $\left({ }^{\circ} \mathrm{C}\right)$

$L_{\mathrm{w}} \quad$ effective plate width (m)

$\dot{m} \quad$ mass flow rate $(\mathrm{kg} / \mathrm{s})$

$\dot{m}_{\mathrm{c}} \quad$ mass flow rate in primary solar circuit, $A_{\mathrm{c}} G(\mathrm{~kg} / \mathrm{s})$

$\dot{m}_{\mathrm{ch}} \quad$ mass flow rate per channel, $\dot{m} / N_{\mathrm{ch}}(\mathrm{kg} / \mathrm{s})$

$\dot{m}_{\mathrm{h}} \quad$ mass flow rate in secondary solar circuit, $A_{\mathrm{c}} G(\mathrm{~kg} / \mathrm{s})$

$\dot{m}_{\mathrm{m}} \quad$ makeup seawater mass flow rate, $\dot{m}_{\mathrm{f}}-\dot{m}_{\mathrm{t}} \quad(\mathrm{kg} / \mathrm{s})$

$\dot{m}_{\mathrm{t}} \quad$ mass flow rate from storage to DCMD modules $(\mathrm{kg} / \mathrm{s})$

$M \quad$ molecular weight $(\mathrm{kg} / \mathrm{kmol})$

$N_{\mathrm{c}} \quad$ number of collectors

$N_{\text {ch }} \quad$ number of channels per pass, $\left(N_{\mathrm{pl}}-1\right) /\left(2 N_{\text {pass }}\right)$

$N_{\text {DM }} \quad$ number of DCMD modules

$N_{\mathrm{f}} \quad$ number of hollow fibers

$N_{\text {pass }} \quad$ total number of passes

$N_{\mathrm{pl}} \quad$ total number of plates, $A_{\mathrm{HX}} / A_{\text {eff }}+2$

$N_{\text {ht }} \quad$ number of heat transfer plates, $N_{\mathrm{pl}}-2$

NTU number of transfer units

$\mathrm{Nu} \quad$ Nusselt number, $h d / k$ for hollow fiber and $h D_{\mathrm{e}} / k_{\mathrm{w}}$ for plate heat exchanger

$p \quad$ plate pitch $(\mathrm{m})$

$P \quad$ pressure $(\mathrm{Pa})$

Pr Prandtl number, $\mu c_{\mathrm{p}} / k$

$P R \quad$ performance ratio

$Q \quad$ heat energy per unit length $(\mathrm{W} / \mathrm{m})$

$q_{\mathrm{a}} \quad$ auxiliary energy required (W)

$Q_{\text {a }} \quad$ auxiliary energy required over a year (J)

$Q_{\mathrm{r}} \quad$ solar energy incident on the collector over a year (J)

$q_{\mathrm{s}} \quad$ load met by solar energy (W)

$Q_{\text {s }} \quad$ load met by solar energy over a year $(\mathrm{J})$

$q_{\mathrm{u}} \quad$ solar useful heat gain rate (W)

$Q_{\mathrm{u}} \quad$ solar useful heat gain rate over a year $(\mathrm{J})$

$r \quad$ water recovery ratio

$r_{\mathrm{m}} \quad$ nominal pore radius $(\mathrm{m})$

$R \quad$ gas constant $\left(\mathrm{J} / \mathrm{kmol}^{\circ} \mathrm{C}\right)$

$R_{\mathrm{b}} \quad$ ratio of beam radiation on a tilted plane to that on the horizontal plane

$R_{\mathrm{K}} \quad$ Knudsen diffusion coefficient $\left(\mathrm{m}^{2} \mathrm{sPa} / \mathrm{kg}\right)$

$R_{\mathrm{M}} \quad$ Molecular diffusion coefficient $\left(\mathrm{m}^{2} \mathrm{sPa} / \mathrm{kg}\right)$

$R_{\mathrm{P}} \quad$ Poiseuille flow coefficient $\left(\mathrm{m}^{2} \mathrm{sPa} / \mathrm{kg}\right)$ 


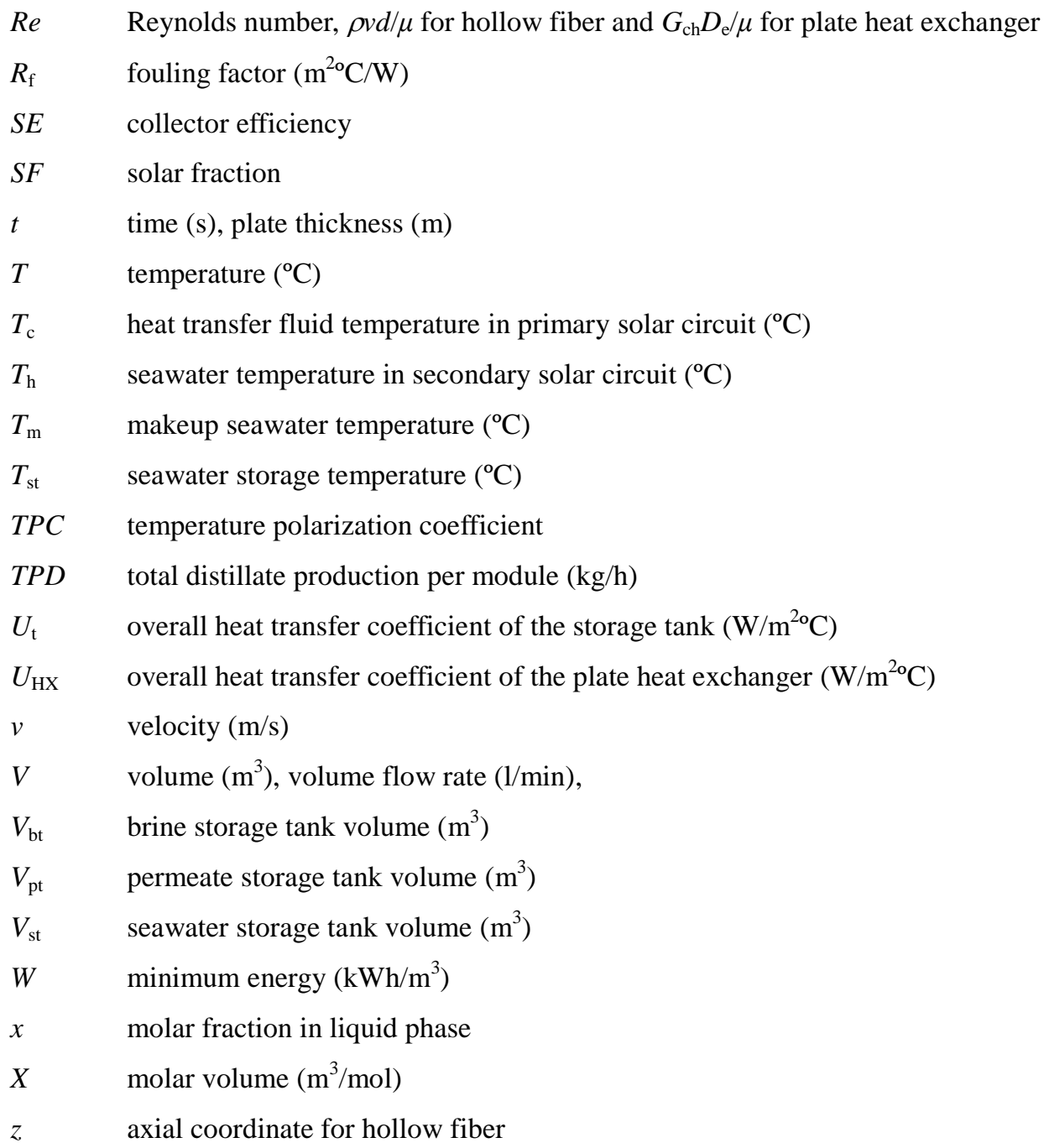

\section{Greek symbols}

$\alpha \quad$ membrane surface area based on fiber inside diameter per unit length per fiber layer $(\mathrm{m})$, yaw angle $\left(^{\circ}\right)$

$\beta \quad$ slope $\left({ }^{\circ}\right)$

$\gamma \quad$ liquid surface tension $(\mathrm{N} / \mathrm{m})$, azimuth angle $\left(^{\circ}\right)$

$\delta_{\mathrm{m}} \quad$ membrane thickness (m)

$\varepsilon \quad$ membrane porosity, effectiveness

$\eta \quad$ local performance ratio, collector efficiency

$\eta_{0} \quad$ optical efficiency

$\theta \quad$ liquid-solid contact angle $\left({ }^{\circ}\right)$, incidence angle $\left({ }^{\circ}\right)$

$\theta_{1} \quad$ incidence angle projection in the longitudinal plane $\left(^{\circ}\right)$

$\theta_{\mathrm{t}} \quad$ incidence angle projection in the transversal plane $\left(^{\circ}\right)$

$\theta_{\mathrm{z}} \quad$ zenith angle $\left(^{\circ}\right)$

$\mu \quad$ dynamic viscosity $(\mathrm{kg} / \mathrm{ms})$

$\pi \quad$ osmotic pressure (Pa) 


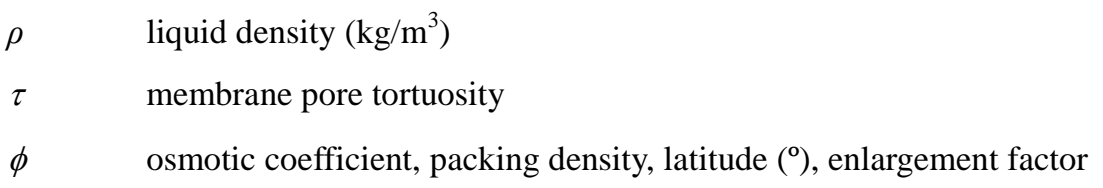

\begin{tabular}{ll}
\multicolumn{2}{l}{ Subscripts } \\
$\mathrm{a}$ & ambient \\
$\mathrm{b}$ & brine \\
$\mathrm{d}$ & distillate \\
$\mathrm{f}$ & feed \\
in & inlet \\
$\mathrm{m}$ & membrane, mean \\
$\mathrm{p}$ & permeate \\
$\mathrm{s}$ & salt \\
$\mathrm{v}$ & vapor \\
$\mathrm{w}$ & water
\end{tabular}

\section{References}

[1] S. Al-Obaidani, E. Curcio, F. Macedonio, G. Di Profio, H. Al-Hinai, E. Drioli, Potential of membrane distillation in seawater desalination: thermal efficiency, sensitivity study and cost estimation, J. Membr. Sci. 323 (2008) 85-98.

[2] M.S. El-Bourawi, Z. Ding, R. Ma, M. Khayet, A framework for better understanding membrane distillation separation process, J. Membr. Sci. 285 (2006) 4-29.

[3] K.W. Lawson, D.R. Lloyd, Membrane distillation, J. Membr. Sci. 124 (1997) 1-25.

[4] L.-H. Cheng, Y.-H. Lin, J. Chen, Enhanced air gap membrane desalination by novel finned tubular membrane modules, J. Membr. Sci. 378 (2011) 398-406.

[5] H. Maab, L. Francis, A. Al-saadi, C. Aubry, N. Ghaffour, G. Amy, S.P. Nunes, Synthesis and facbrication of nanostructured hydrophobic polyazole membranes for low-energy water recovery, J. Membr. Sci. doi: 10.1016/j.memsci.2012.07.009.

[6] B. Li, K.K. Sirkar, Novel membrane and device for direct contact membrane distillation-based desalination process, Ind. Eng. Chem. Res. 43 (2004) 5300-5309.

[7] T.Y. Cath, V.D. Adams, A.E. Childress, Experimental study of desalination using direct contact membrane distillation: a new approach to flux enhancement, J. Membr. Sci. 228 (2004) 5-16.

[8] H.F. Mark, Encyclopedia of Polymer Science and Technology, 4th ed., John Wiley \& Sons, 2009.

[9] Z. Ding, L. Liu, R. Ma, Study on the effect of flow maldistribution on the performance of hollow fiber module used in membrane distillation, J. Membr. Sci. 215 (2003) 11-23.

[10] J. Zheng, Z. Xu, J. Li, S. Wand, Y. Xu, Influence of random arrangement of hollow fiber membranes on shell side mass transfer performance: a novel model prediction, J. Membr. Sci. 236 (2004) 145151.

[11] F. Banat, R. Jumah, M. Garaibeh, Exploitation of solar energy collected by solar stills for 
desalination by membrane distillation, Renew. Energy 25 (2002) 293-305.

[12] Z. Ding, L. Liu, M.S. El-Bourawi, R. Ma, Analysis of a solar-powered membrane distillation system, Desalination 172 (2005) 27-40.

[13] J. Koschikowski, M. Wieghaus, M. Rommel, Solar thermal-driven desalination plants based on membrane distillation, Desalination 156 (2003) 295-304.

[14] E. Guillén-Burrieza, J. Blanco, G. Zaragoza, D.-C. Alarcón, P. Palenzuela, M. Ibarra, W. Gernjak, Experimental analysis of an air gap membrane distillation solar desalination pilot system, J. Membr. Sci. 379 (2011) 386-396.

[15] T.-C. Chen, C.-D. Ho, Immediate assisted solar direct contact membrane distillation in saline water desalination, J. Membr. Sci. 358 (2010) 122-130.

[16] H.J. Zwijnenberg, G.H. Koops, M Wessling, Solar driven membrane pervaporation for desalination processes, J. Membr. Sci. 250 (2005) 235-246.

[17] M.R. Qtaishat, F. Banat, Desalination by solar powered membrane distillation systems, Desalination 10.1016/j.desal.2012.01.021.

[18] R.W. Stoughton, M.H. Lietzke, Calculation of some thermodynamic properties of sea salt solutions at elevated temperatures from data on $\mathrm{NaCl}$ solutions, J. Chem. Eng. Data 10 (1965) 254-260.

[19] K.S. Spiegler, Y.M. El-Sayed, A Desalination Primer, Balaban Desalination Publications, Santa Maria Imbaro, 1994.

[20] K.P. Lee, T.C. Arnot, D. Mattia, A review of reverse osmosis membrane materials for desalination development to date and future potential, J. Membr. Sci. 370 (2011) 1-22.

[21] J.E. Miller, Review of water resources and desalination technologies, Sandia national laboratories, (2003) http://prod.sandia.gov/techlib/access-control.cgi/2003/030800.pdf

[22] W.M. Kays, Numerical solutions for laminar-flow heat transfer in circular tubes, Trans. ASME 77 (1955) 1265-1274.

[23] H. Hausen, Darstellung des wärmeüberganges in rohren durch verallgemeinerte potenzbeziehyngen, Z. VDI Beih. Verfahrenstech. 4 (1943) 91-98.

[24] H.G. Groehn, Influence of the yaw angle on heat transfer and pressure drop of tube bundle heat exchangers, Heat Transf. 6 (1982) 203-209.

[25] R. Thanedgunbaworn, R. Jiraratananon, M.H. Nguyen, Shell-side mass transfer of hollow fibre modules in osmotic distillation process, J. Membr. Sci. 290 (2007) 105-113.

[26] C. Gostoli, G.C. Sarti, S. Matulli, Low temperature distillation through hydrophobic membranes, Sep. Sci. Technol. 22 (1987) 855-872.

[27] E. Curcio, E. Drioli, Membrane distillation and related operations - a review, Sep. Purif. Rev. 34 (2005) 35-86.

[28] R.M. Felder, R.W. Rousseau, Elementary Principles of Chemical Processes, $3^{\text {rd }}$ ed., John Wiley \& Sons, New York, 2000.

[29] Z. Ding, R. Ma, A.G. Fane, A new model for mass transfer in direct contact membrane distillation, Desalination 151 (2002) 217-227.

[30] J. Phattaranawik, R. Jiraratananon, A.G. Fane, Effect of pore size distribution and air flux on mass 
transport in direct contact membrane distillation, J. Membr. Sci. 215 (2003) 75-85.

[31] R.W. Schofield, A.G. Fane, C.J.D. Fell, Gas and vapour transport through microporous membranes. I. Knudsen-Poiseuille transition, J. Membr. Sci. 53 (1990) 159-171.

[32] L.-H. Cheng, P.-C. Wu, J. Chen, Modeling and optimization of hollow fiber DCMD module for desalination, J. Membr. Sci. 318 (2008) 154-166.

[33] E.N. Fuller, P.D. Schettler, J.C. Giddings, New method for prediction of binary gas-phase diffusion coefficients, Ind. Eng. Chem. 58 (1966) 18-27.

[34] F. Laganà, G. Barbieri, E. Drioli, Direct contact membrane distillation: modeling and concentration experiments, J. Membr. Sci. 166 (2000) 1-11.

[35] M.H. Sharqawy, J.H. Lienhard V, S.M. Zubair, Thermophysical properties of seawater: a review of existing correlations and data, Desalin. Water Treat. 16 (2010) 354-380.

[36] C.G. Broyden, A class of methods for solving nonlinear simultaneous equations, Math. Comput. 19 (1965) 577-593.

[37] P.W. Stackhouse, C.H. Whitlock, Surface meteorology and Solar Energy (SSE) rel. 6.0, NASA, (2010) http://eosweb.larc.nasa.gov/sse/.

[38] M. Collares-Pereira, A. Rabl, The average distribution of solar radiation-correlations between diffuse and hemispherical and between daily and hourly insolation values, Sol. Energy 22 (1979) 155-164.

[39] B.Y.H. Liu, R.C. Jordan, The interrelationship and characteristic distribution of direct, diffuse and total solar radiation, Sol. Energy 4 (1960) 1-19.

[40] J.E. Hay, J.A. Davies, Calculation of the solar radiation incident on an inclined surface, Proc. First Canadian Solar Radiation Data Workshop (1980) 59-72.

[41] R.C. Temps, K.L. Coulson, Solar radiation incident upon slopes of different orientations, Sol. Energy 19 (1977) 179-184.

[42] T.M. Klucher, Evaluation of models to predict insolation on tilted surfaces, Sol. Energy 23 (1979) $111-114$.

[43] D.T. Reindl, W.A. Beckman, J.A. Duffie, Evaluation of hourly tilted surface radiation models, Sol. Energy 45 (1990) 9-17.

[44] Y.-D. Kim, K. Thu, H.K. Bhatia, C.S. Bhatia, K.C. Ng, Thermal analysis and performance optimization of a solar hot water plant with economic evaluation, Sol. Energy 86 (2012) 1378-1395.

[45] Weather Underground, (2010) http://www.wunderground.com/.

[46] Y.-D. Kim, W.-S. Kim, Re-evaluation and modeling of a commercial diesel oxidation catalyst, Ind. Eng. Chem. Res. 48 (2009) 6579-6590.

[47] A. Rabl, Active Solar Collectors and their Applications, Oxford University Press, Oxford, 1985.

[48] W.R. McIntire, Factored approximations for biaxial incident angle modifiers, Sol. Energy 29 (1982) 315-322.

[49] EN 12975-2:2006. Thermal solar systems and components - Solar collectors - Part 2: Test Methods, Section 6.1. European Standard, March.

[50] Kingspan Solar Inc. (2012) http://www.kingspan-thermomax.com/. 
[51] R.P. Singh, D.R. Heldman, Introduction to Food Engineering, Elsevier Inc., London, 2008.

[52] H. Kumar, The plate heat exchanger: construction and design, Proc. first UK National Conference on Heat Transfer (1984) 1275-1288.

[53] A.C.M. Franken, J.A.M. Nolten, M.H.V. Mulder, D. Bargeman, C.A. Smolders, Wetting criteria for the applicability of membrane distillation, J. Membr. Sci. 33 (1987) 315-328.

[54] M. Khayet, M.P. Godino, J.I. Mengual, Study of asymmetric polarization in direct contact membrane distillation, Sep. Sci. Technol. 39 (2005) 125-147.

[55] M. Khayet, M.P. Godino, J.I. Mengual, Thermal boundary layers in sweeping gas membrane distillation processes, AIChE J. 48 (2004) 1488-1497.

[56] E. Guillén-Burrieza, G. Zaragoza, S. Miralles-Cuevas, J. Blanco, Experimental evaluation of two pilot-scale membrane distillation modules used for solar desalination, J. Membr. Sci. 409-410 (2012) $264-275$.

[57] C.R. Marinetti, A.E. Childress, T.Y. Cath, High recovery of concentrated RO brines using forward osmosis and membrane distillation, J. Membr. Sci. 331 (2009) 31-39.

[58] J. Zhang, N. Dow, M. Duke, E. Ostarcevic, J.-D. Li, S. Gray, Identification of material and physical features of membrane distillation membranes for high performance desalination, J. Membr. Sci. 349 (2010) 295-303.

[59] M. Gryta, Fouling in direct contact membrane distillation process, J. Membr. Sci. 325 (2008) 393394.

[60] J. Wu, V. Chen, Shell-side mass transfer performance of randomly packed hollow fiber modules, J. Membr. Sci. 172 (2000) 59-74.

[61] X. Yang, R. Wang, L. Shi, A.G. Fane, M. Debowski, Performance improvement of PVDF hollow fiber-based membrane distillation process, J. Membr. Sci. 369 (2011) 437-447.

[62] J. Günther, D. Hobbs, C. Albasi, C. Lafforgue, A. Cockx, P. Schmitz, Modeling the effect of packing density on filtration performances in hollow fiber microfiltration module: a spatial study of cake growth, J. Membr. Sci. 389 (2012) 126-136.

[63] H.J. Hwang, K. He, S. Gray, J. Zhang, I.S. Moon, Direct contact membrane distillation (DCMD): experimental study on the commercial PTFE membrane and modeling, J. Membr. Sci. 371 (2011) 90-98.

\section{Table captions}

Table 1 Operating strategy of the solar hot seawater system.

Table 2 Characteristics and operating conditions of the shell-and-tube type hollow fiber membrane module.

Table 3 Parameters and input data for the solar-assisted DCMD desalination system. 
Table 4 Summary of STEC and SEEC with respect to collector area for the solar-assisted DCMD desalination system.

\section{Figure captions}

Fig. 1. Minimum work for the desalination of seawater with the salt concentration of 4.5 wt $\%$ at the temperatures of $25^{\circ} \mathrm{C}$ and $80^{\circ} \mathrm{C}$.

Fig. 2. Schematic of solar-assisted DCMD desalination system with the HR and TM units.

Fig. 3. Schematic of (a) shell-and-tube type DCMD module and (b) heat and mass transfer through hollow fiber in DCMD process.

Fig. 4. Schematic of mass transport mechanism through the hollow fiber.

Fig. 5. Monthly average hourly (a) ambient temperature and (b) global irradiance on the tilted surface in Jeddah, Saudi Arabia.

Fig. 6. Feed and permeate velocities as a function of fiber length axial position $\left(w_{\mathrm{f}, \text { in }}=0.045, T_{\mathrm{f} \text {,in }}=80^{\circ} \mathrm{C}\right.$, $\left.V_{\mathrm{f}, \text { in }}=6 \mathrm{l} / \mathrm{min}, T_{\mathrm{p}, \text { in }}=30^{\circ} \mathrm{C}, V_{\mathrm{p}, \text { in }}=6 \mathrm{l} / \mathrm{min}, L_{\mathrm{f}}=0.4, \phi=0.59\right)$.

Fig. 7. Pressures of the bulk feed and permeate and at the feed and permeate sides of membrane as a function of fiber length axial position $\left(w_{\mathrm{f}, \text { in }}=0.045, T_{\mathrm{f}, \text { in }}=80^{\circ} \mathrm{C}, V_{\mathrm{f}, \text { in }}=6 \mathrm{l} / \mathrm{min}, T_{\mathrm{p} \text {,in }}=30^{\circ} \mathrm{C}, V_{\mathrm{p}, \text { in }}=6\right.$ $\left.1 / \min , L_{\mathrm{f}}=0.4, \phi=0.59\right)$.

Fig. 8. (a) Temperatures of the bulk feed and permeate and at the feed and permeate sides of membrane and (b) temperature polarization as a function of fiber length axial position $\left(w_{\mathrm{f}, \text { in }}=0.045, T_{\mathrm{f}, \mathrm{in}}=80^{\circ} \mathrm{C}\right.$, $\left.V_{\mathrm{f}, \text { in }}=6 \mathrm{l} / \mathrm{min}, T_{\mathrm{p}, \text { in }}=30^{\circ} \mathrm{C}, V_{\mathrm{p}, \text { in }}=6 \mathrm{l} / \mathrm{min}, L_{\mathrm{f}}=0.4, \phi=0.59\right)$.

Fig. 9. Permeate flux and performance ratio as a function of fiber length axial position $\left(w_{\mathrm{f}, \text { in }}=0.045, T_{\mathrm{f}, \text { in }}\right.$ $\left.=80^{\circ} \mathrm{C}, V_{\mathrm{f}, \text { in }}=6 \mathrm{l} / \mathrm{min}, T_{\mathrm{p}, \text { in }}=30^{\circ} \mathrm{C}, V_{\mathrm{p}, \text { in }}=61 / \mathrm{min}, L_{\mathrm{f}}=0.4, \phi=0.59\right)$.

Fig. 10. Salt concentration as a function of fiber length axial position $\left(w_{\mathrm{f}, \text { in }}=0.045, T_{\mathrm{f} \text {,in }}=80^{\circ} \mathrm{C}, V_{\mathrm{f} \text {,in }}=6\right.$ $\left.1 / \mathrm{min}, T_{\mathrm{p}, \text { in }}=30^{\circ} \mathrm{C}, V_{\mathrm{p}, \text { in }}=6 \mathrm{l} / \mathrm{min}, L_{\mathrm{f}}=0.4, \phi=0.59\right)$.

Fig. 11. Effect of the bulk feed and permeate temperatures on (a) transmemebrane pressure at feed side, (b) transmemebrane pressure at permeate side, (c) mean permeate flux and (d) performance ratio $\left(w_{\mathrm{f}, \text { in }}=\right.$ $\left.0.045, V_{\mathrm{f}, \text { in }}=6 \mathrm{l} / \mathrm{min}, V_{\mathrm{p}, \text { in }}=6 \mathrm{l} / \mathrm{min}, L_{\mathrm{f}}=0.4, \phi=0.59\right)$.

Fig. 12. Effect of the bulk feed and permeate flow rates on (a) transmemebrane pressure at feed side, (b) transmemebrane pressure at permeate side, (c) mean permeate flux and (d) performance ratio $\left(w_{\mathrm{f}, \text { in }}=\right.$ $\left.0.045, T_{\mathrm{f}, \text { in }}=80^{\circ} \mathrm{C}, T_{\mathrm{p}, \text { in }}=30^{\circ} \mathrm{C}, L_{\mathrm{f}}=0.4, \phi=0.59\right)$.

Fig. 13. Effect of the fiber length and the packing density on (a) transmemebrane pressure at feed side, (b) transmemebrane pressure at permeate side, (c) mean permeate flux and (d) performance ratio $\left(w_{\mathrm{f}, \text { in }}=\right.$ $\left.0.045, T_{\mathrm{f}, \text { in }}=80^{\circ} \mathrm{C}, V_{\mathrm{f}, \mathrm{in}}=6 \mathrm{l} / \mathrm{min}, T_{\mathrm{p}, \text { in }}=30^{\circ} \mathrm{C}, V_{\mathrm{p}, \text { in }}=6 \mathrm{l} / \mathrm{min}\right)$.

Fig. 14. Effect of the fiber length and the packing density on total distillate production $\left(w_{\mathrm{f}, \text { in }}=0.045, T_{\mathrm{f}, \mathrm{in}}\right.$ $\left.=80^{\circ} \mathrm{C}, V_{\mathrm{f}, \text { in }}=61 / \mathrm{min}, T_{\mathrm{p}, \text { in }}=30^{\circ} \mathrm{C}, V_{\mathrm{p}, \text { in }}=61 / \mathrm{min}\right)$.

Fig. 15. Effect of the solar collector area with the storage tank volume of $160 \mathrm{~m}^{3}$ on four mean storage temperatures, instantaneous efficiency of solar collector over the 3 days from 14th to 16th January; (a) $A_{\mathrm{c}}$ $=1983 \mathrm{~m}^{2}$; (b) $A_{\mathrm{c}}=2439 \mathrm{~m}^{2}$; (c) $A_{\mathrm{c}}=2898 \mathrm{~m}^{2}$; (d) $A_{\mathrm{c}}=3360 \mathrm{~m}^{2}\left(N_{\mathrm{DM}}=50, w_{\mathrm{f}, \text { in }}=0.045, T_{\mathrm{f}, \mathrm{in}}=80^{\circ} \mathrm{C}\right.$, 
$\left.\dot{m}_{\mathrm{f}}=5 \mathrm{~kg} / \mathrm{s}, T_{\mathrm{p}, \mathrm{in}}=30^{\circ} \mathrm{C}, \dot{m}_{\mathrm{p}}=5 \mathrm{~kg} / \mathrm{s}, L_{\mathrm{f}}=0.4, \phi=0.59\right)$.

Fig. 16. Effect of the collector area and the seawater storage volume on annual (a) solar fraction and (b) collector efficiency $\left(N_{\mathrm{DM}}=50, w_{\mathrm{f}, \mathrm{in}}=0.045, T_{\mathrm{f}, \mathrm{in}}=80^{\circ} \mathrm{C}, \dot{m}_{\mathrm{f}}=5 \mathrm{~kg} / \mathrm{s}, T_{\mathrm{p}, \text { in }}=30^{\circ} \mathrm{C}, \dot{m}_{\mathrm{p}}=5 \mathrm{~kg} / \mathrm{s}, L_{\mathrm{f}}=0.4\right.$, $\phi=0.59$ ). NR (nonfeasible region) depicts the system configurations where the seawater storage temperature does exceed the water boiling temperature.

Fig. 17. Effect of the collector area with the storage tank volume of $160 \mathrm{~m}^{3}$ on annual solar fraction and collector efficiency $\left(N_{\mathrm{DM}}=50, w_{\mathrm{f}, \text { in }}=0.045, T_{\mathrm{f}, \text { in }}=80^{\circ} \mathrm{C}, \dot{m}_{\mathrm{f}}=5 \mathrm{~kg} / \mathrm{s}, T_{\mathrm{p}, \text { in }}=30^{\circ} \mathrm{C}, \dot{m}_{\mathrm{p}}=5 \mathrm{~kg} / \mathrm{s}, L_{\mathrm{f}}=0.4\right.$, $\phi=0.59)$.

Fig. 18. Effect of the collector area and the seawater storage volume on specific thermal energy consumption $\left(N_{\mathrm{DM}}=50, w_{\mathrm{f}, \text { in }}=0.045, T_{\mathrm{f}, \text { in }}=80^{\circ} \mathrm{C}, \quad \dot{m}_{\mathrm{f}}=5 \mathrm{~kg} / \mathrm{s}, T_{\mathrm{p}, \text { in }}=30^{\circ} \mathrm{C}, \dot{m}_{\mathrm{p}}=5 \mathrm{~kg} / \mathrm{s}, L_{\mathrm{f}}=0.4, \phi=\right.$ $0.59)$. 